\title{
The Plague in Islamic and Abbasid Poetry
}

\author{
Ahmad Mahmood Abdulhameed Al-Bayaati \\ Department of Arabic Language, College of Education in Al-Qayim, University of Anbar, Iraq \\ ahmad.albayati@uoanbar.edu.iq
}

\section{KEYWORDS: $\quad$ Plague, Poetry, Islamic, Abbasid, Outbreak.}

\begin{abstract}
:
The great spread of the plague in the Arab countries and the severity of their fear of it and their feeling of helplessness in the face of its oppression made them attribute it to the jinn, and they preferred to live in the arid desert over the countries that they saw as humid as the Levant, fleeing from it because they believed that it was abundant in them, so the abundance of his names to them, perhaps the most prominent thing that appeared in the poetry of the plague is an emotion Sadness and pain for loved ones and relatives, and lamentations abounded in it, and a number of the most famous Arab lamentations were said because of it, and the lament included people and cities because of the devastation that befell them by plagues, almost all of the poetry dealt with the subject of the plague said after the emergence of Islam. Therefore, its impact was evident in it, such as the joy of dying from the plague because it is a testimony, and God collected the stabbing and plague on the nation influenced by the Prophet's hadith, and others. Most of his poetic texts describe the state of loss and grief, in the face of the devastation and killing that the plague does, and it is rare to find a description of it, so the poet focused on the emotional side of this tragedy, were it not for the elegy poems we received. Short texts (syllables and plucking) would have been dominant, as they are partial glimpses and images that pass in front of the poet and record them. Poets used the image of the plague to express the pain of their love and spin, and in their sarcastic and serious humorous attacks, describing their brutality and the strength and intensity of their praises.
\end{abstract}




\title{
الطاعون في الشعر الإسلامي والعباسي
}

\author{
أحمد محمود عبدالحميد البياتي \\ قسم اللغة العربية، كلية التربية القائم، جامعة الأنبار، العراق اقليميل \\ ahmad.albayati@uoanbar.edu.iq
}

الكلمات المفتاحية | الطاعون، الشعر، الإسلامي، العباسي، تفشي.

Crossref doi https://doi.org/10.51345/.v32i2.335.g218

\section{ملخص البحث: - مثن}

كثر تفشي الطاعون في بلاد العرب وشدة خوفهم منه وشعورهم بالعجز أمام بطشه مما جعلهم ينسبونه إلى الجن، وفضلوا العيش

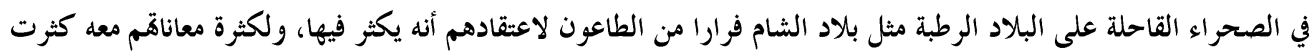

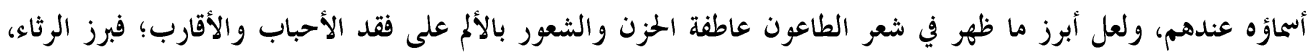

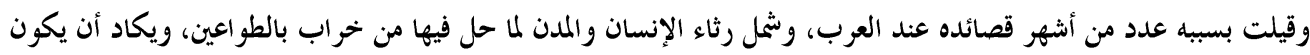
كل الشعر الذي عاج موضوع الطاعون قيل بعد ظهور الإسلام؛ لذا ظهر أثره جليا فيه، كالفرح بالموت مطعوناً لأنه شهادة، وجمع الله الطعن والطاعون على الأمة تأثرا بحديث للرسول، وغيرها. جل نصوصه الشعرية تصف حالة الفقد والحزن، تجاه ما يفعله الطاعون من خراب وقتل، وندر أن نجد وصفا للمرض ذاته، فالشاعر ركز على الجانب الوجدابي في هذه المأساة، وأكثر النصوص التي وقفنا عليها كانت قصيرة (المقطعات والنتف) وهي الغالبة، فهي لمحات وصور جزئية تمر أمام الشاعر فيسجلها. استخدم الشعراء صورة الطاعون في التعبير عن آلام حبهم وغزلهم، وفي مهاجيهم الفكاهية الساخرة والجادة، ووصف بطشئهم وقوة وشدة ممدوحيهم، ما قيل من شعر في وصف الطاعون جاء صادق المشاعر والأحاسيس، بعيدا عن الصنعة والتكلف، معبرا

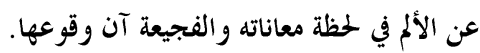

المقدمة:

توطئة: تعريف بالطاعون وأسمائه عند العرب وموقفهم منه:

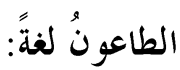

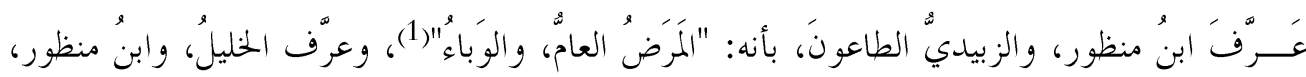

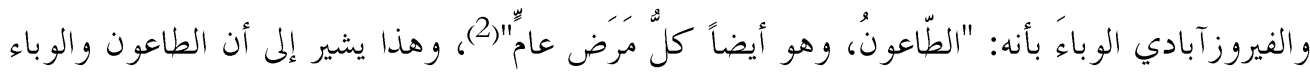

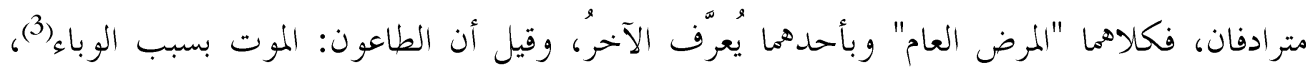

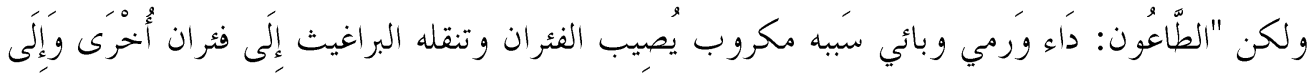


الْإِنْسَان (ج) طواعين"(4)، فلعل الكلمة كانت تستخدم بالمعنى العام المرادف للوباء أو المرض العام، كما أن دلالتها خصصت بالمرض المحدد الصفات والأعراض، ولقد قال ابن القيم: "والتحقيق أن بين الوباء و الطاعون عموماً وخصوصاً. ..فكل طاعون و باء، وليس كل وباء طاعونا"(5.).

\section{كنى الطاعون، وأسماؤه:}

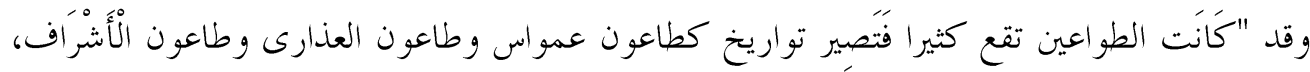
وغيرها"(6)، ولهذا كثرت أسماؤه و كنهاه، ومنها:

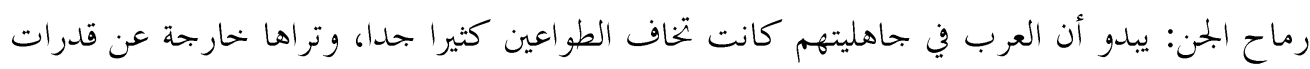
البشر ولا يمكن لهم مواجهتها، لذا نسبوها إلى الجن كعادهم عندما يحارون في أمر ويعجزهم بفعاله،

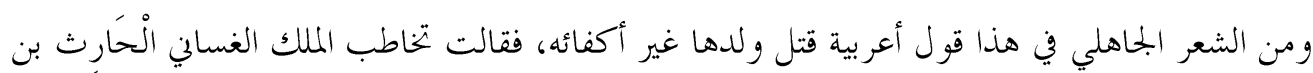

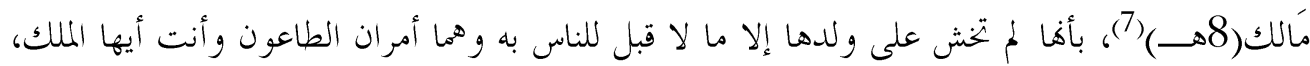

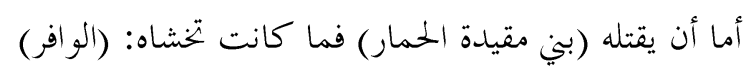

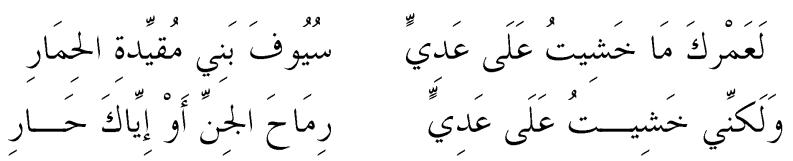

رماح الجنّ: كناية عن الطاعون(8)، وهذان البيتان أقدم بيتين وقفت عليهما في ذكر الطاعون.

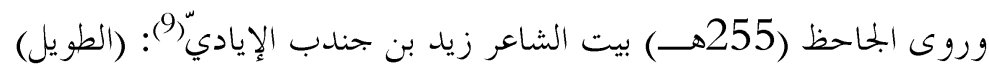

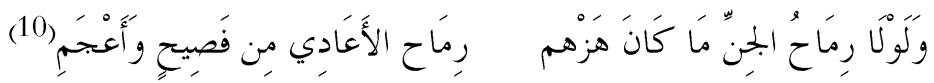

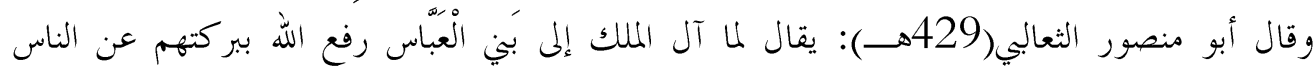

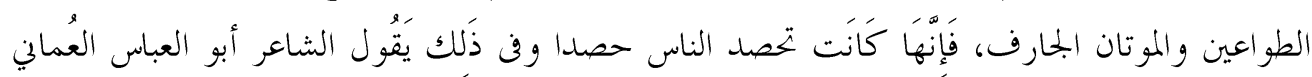

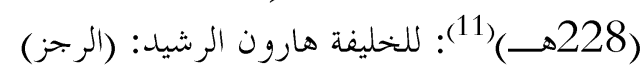

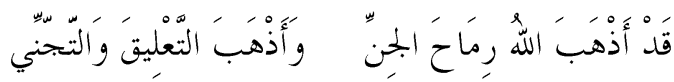

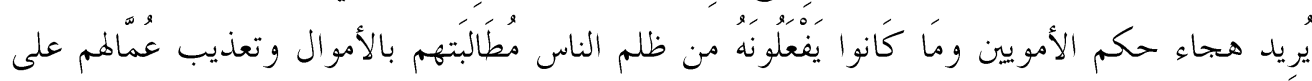

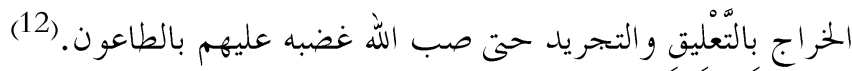

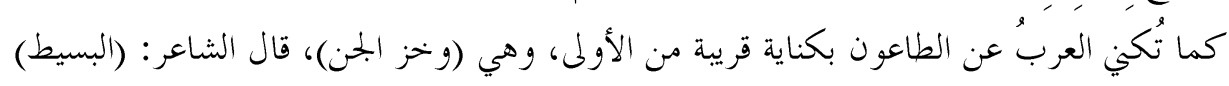

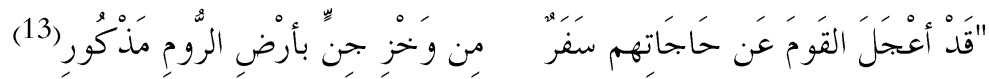

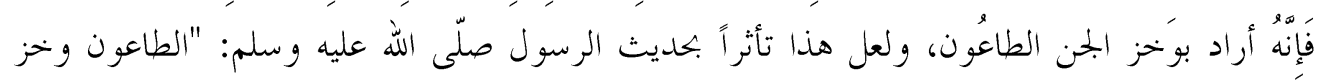
أعدائكم من الجن وهو كلم شهادة"(14). 


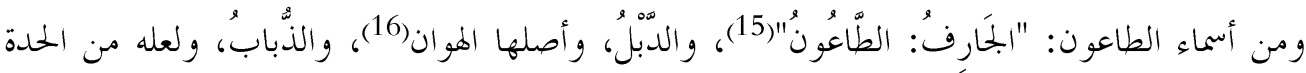

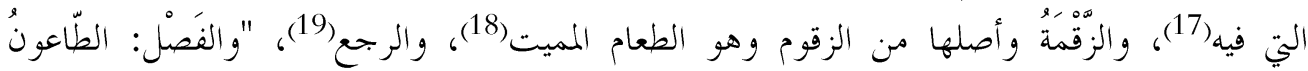

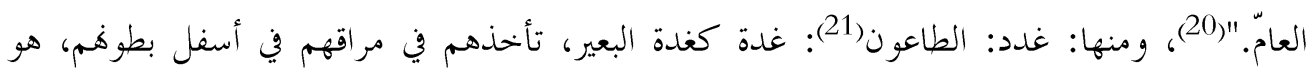

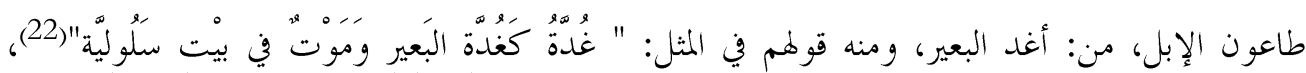

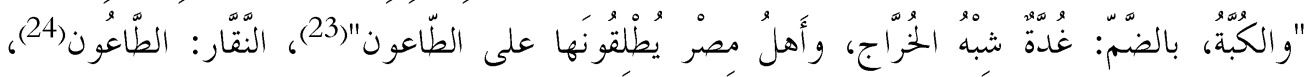

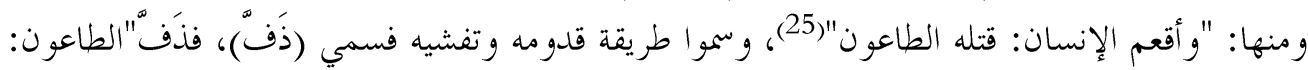

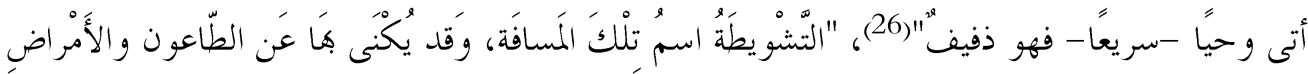

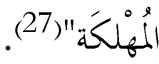

وبلغ بالعرب خحوفهم من الطاعون حد أهم فضلوا العيش في الصحارى والبوادي على كثرة غبارها

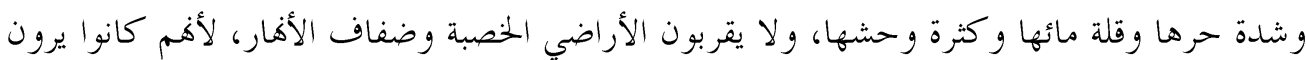

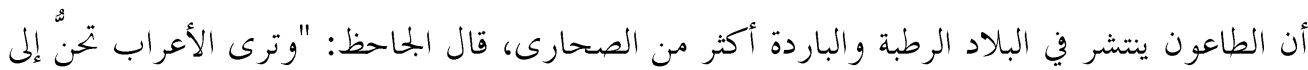

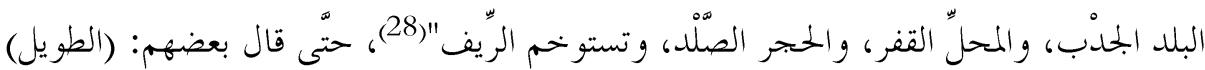

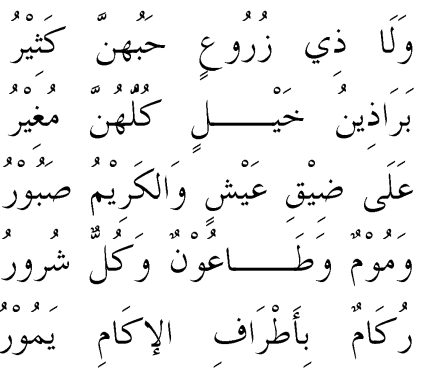

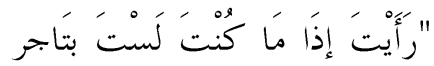

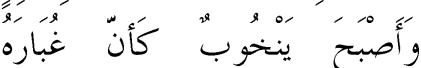

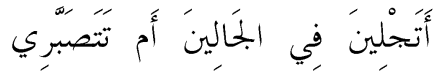

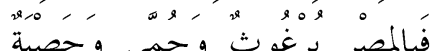

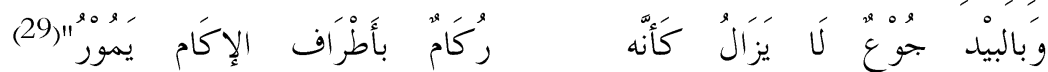

وكانوا يرون أن أرض السواد "بلد وباء"(30)، فقال الشاعر يصف حال من يتزل العراق ويقيم فيه بأن

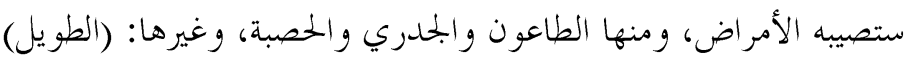

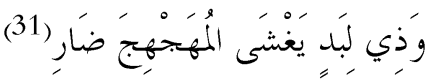

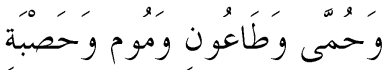

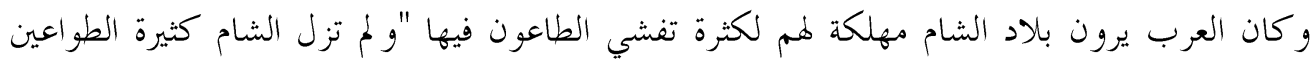

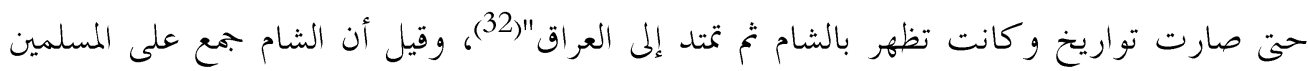

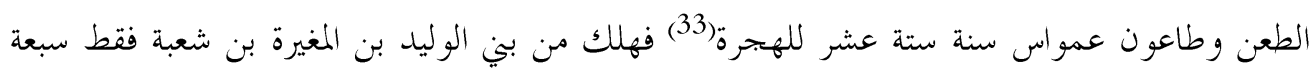

وسبعون رجلا، فقال المهاجر بن خالد بن الوليد بن المغيرة: (السريع)

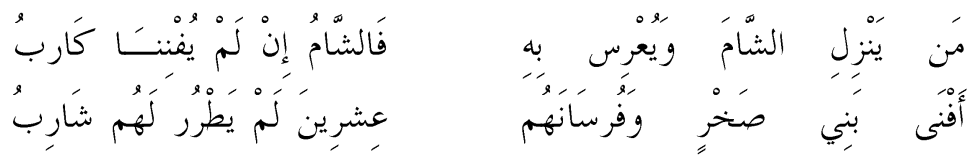




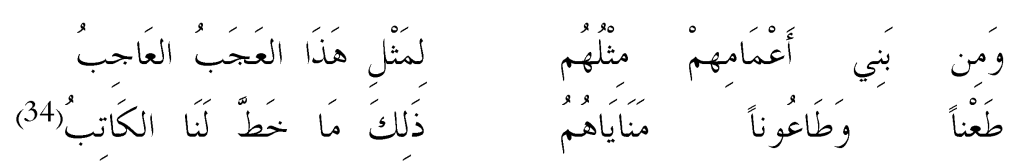

فالشاعر يرى أن الشام إن لم يفنهم فقد كارب (قارب) أن يفعل، ثم أخذ يعدد أقواما قد أهلكهم الشام بطو اعينه، وطعنه. لذا كره العرب الطاعون، وأصبحوا يدعون به على المدن العامرة، لأهم يعلمون أنه سيحل الخراب و الهلاكك بها، و من هذا قول أبي الحسن الواصلي الكاتب: (الخفيف)

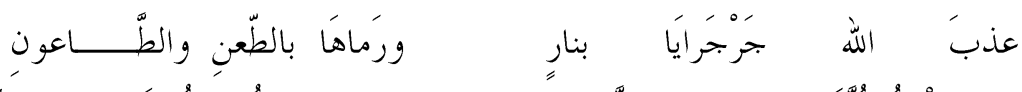

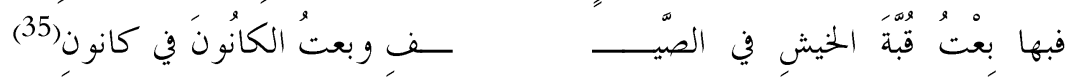
واشتهر الشاعر عبد الله بن أبي الشيص بأنه سكن بسر من رأى على كره فكثر ذمه لها والدعاء عليها، و منه قوله: (الخفيف) لعنَ اللهّ سرّه منْ را بلاداً فالعرب آمنت بأن الطاعون داء لا دواء له ولا منجى منه، لذا قال الأخطل التغلبي وهو يريد أن يشبه نفسه وشعره بأعتى الأشياء طرا وأكثرها فتكا ليسبق غريميه جرير بن عطية والفرزدق، فشبه نفسه بالطاعون فقال رادا على الفرزدق و متحديا جرير بن عطية: (الوافر)

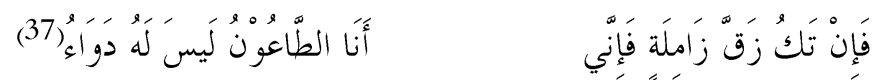
وقال جلال الدين السيوطي (ت 911هـ) في مقامته: (البسيط) لكل داء دواء يستطب به

المبحث الأول: وصف الطاعون:

لا يمكن أن تعاني الأمة العربية من الطاعون على مدى قرون من دون أن يعبر أدباؤها عن هذا كل وفق معاناته مع هذا الوباء، وقد كتب عدد من الأدباء رسائل ومقامات تصور الطاعون وتفشيه، منها: (رسالة النبا عن الوبا) لابن الوردي (ت 749هــ)(39)، وكتابات لابن أبي حجلة (ت 776هــ(40)،

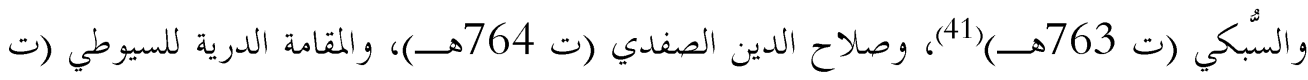
911هـ)، ولقد جمعت كلها في كتاب بذل الماعون في فضل الطاعون لأحمد بن حجر العسقالاني(42. أما في الشعر فإن ما قاله شعراء العربية مبثوث في كتب الأدب و اللغة، وهو يعبر عن معاناة الشاعر نتيجة لإصابته بداء الطاعون، أو لفقده من يحب ويعرف من الأهل والأحباب، أو يكون الشعر تعبيرا عن المأساة التي أصابت الأمة، وغيرها من المو اقف. 
لم يعن الشاعر بوصف هيئة المصاب بالطاعون كلون وجه المصاب وما تظهر عليه وعلى بدنه من علامات، ولا ارتفاع حرارة الجساد، ولا الحديث عن كيفية الشفاء من الطاعون بقدر ما يعنيه التعبير عن المأساة وتصويرها، تلك المأساة التي يخلفها الطاعون هلاك وبوار للبشر وفقد الأهل والأصحاب

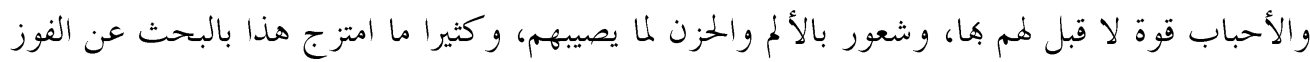

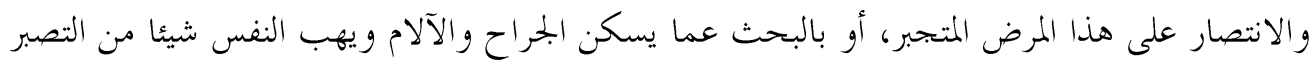

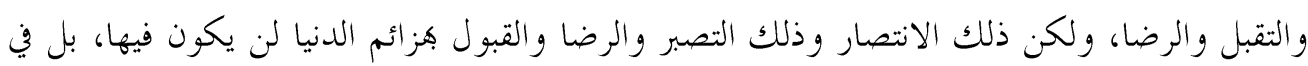

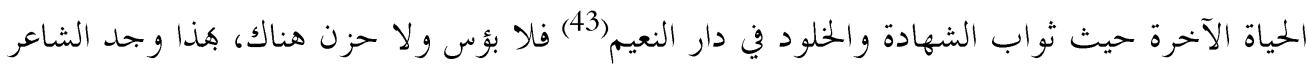

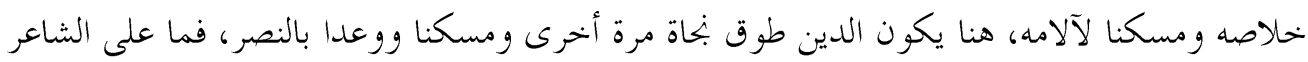

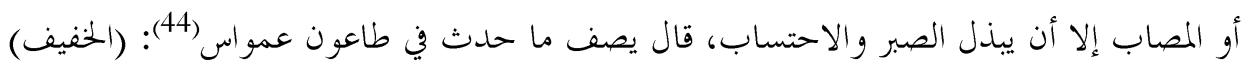

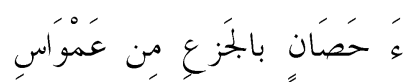

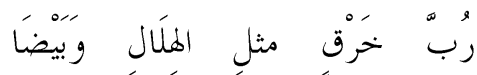

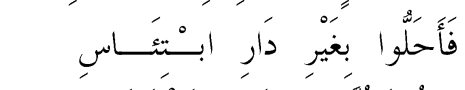

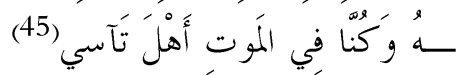

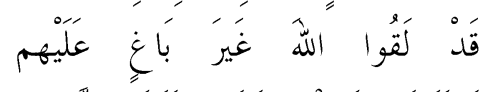

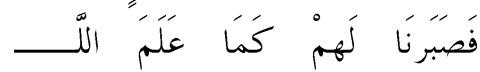
الشاعر يحزن على من مات على كثرهم فهم رجال بكل معاني الرجولة، ونساء ذوات عفاف وجمال

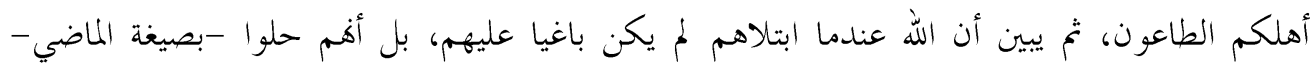
وانتقلوا إلى دار لا بؤس ولا حزن فيها، ونحن من بقي من بعدهم نصبر على هذا المصاب، وهذا علام

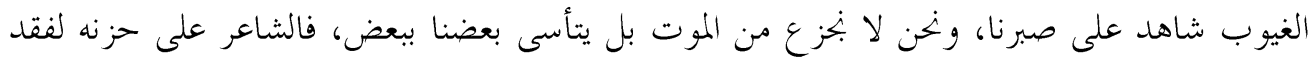

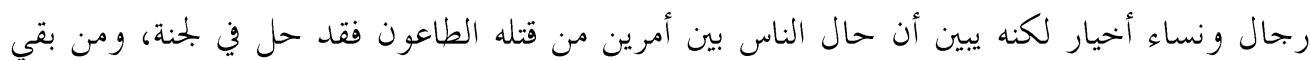

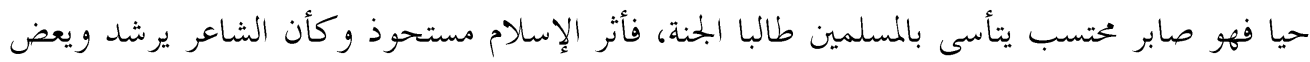
الناس ويدعوهم إلى التوجه إلى الله، ولا عجب في هذا خاصة إذا علمنا أن الأبيات نسبت لشعراء

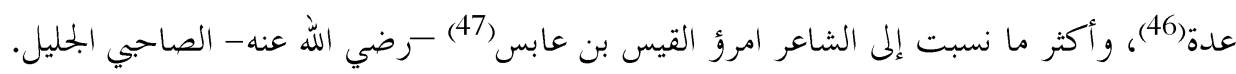

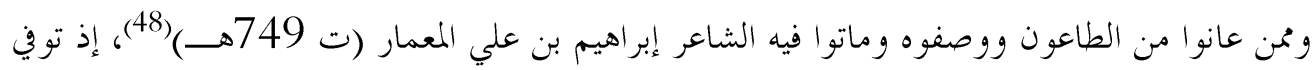

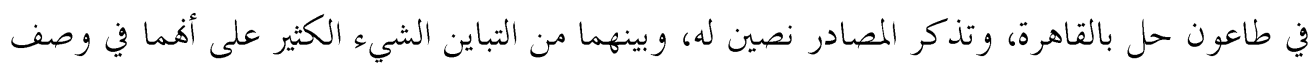

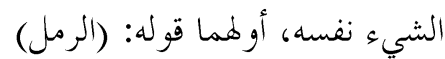

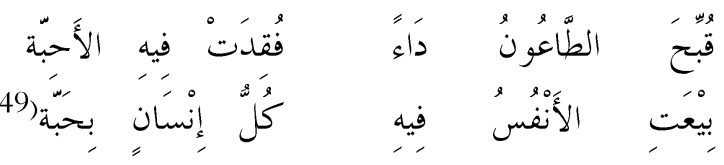


بيتان يعبران عن حزن وألم كبيرين، إذ أنه يدعو على الطاعون أن يقبحه الله، و كأنه يواجه العدو الذي

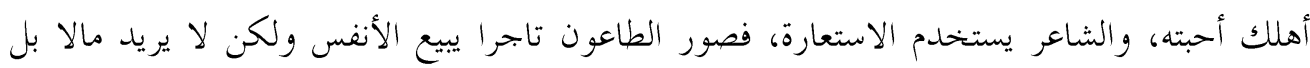

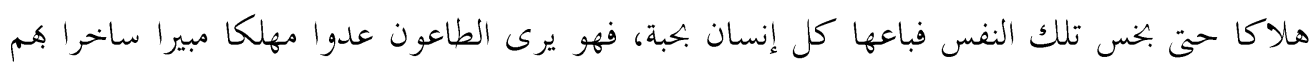
يلتذ بإهلاك الأحبة، وهذه الصورة لا بجدها تتوافق مع إبراهيم المعمار الشاعر الظريف الماجن، وقد فئد

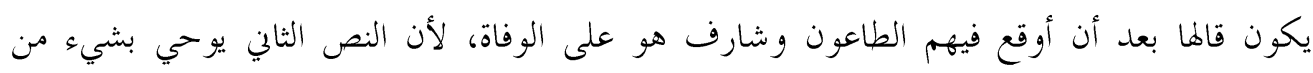
التعريض، قال: (السريع)

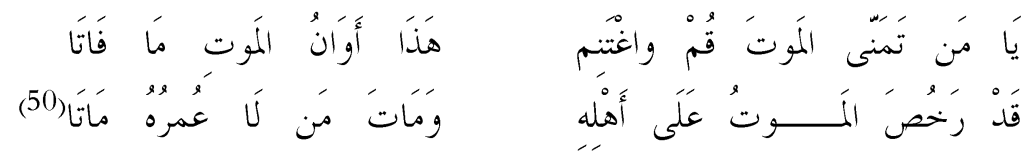
فكأن الشاعر يعرض بمن كان يريد الموت والسعي إلى الجنان والخلد فيها، فيخاطبهم بأن هذا أوان الموت

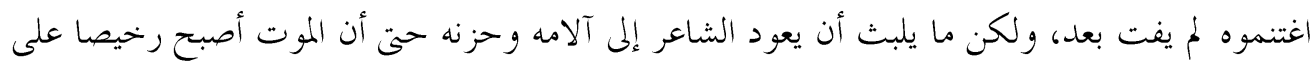

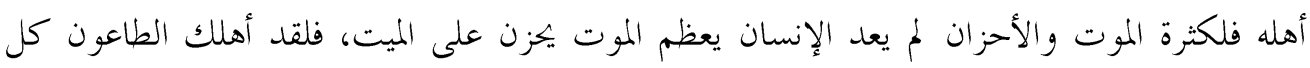

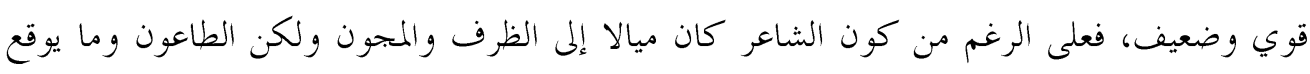

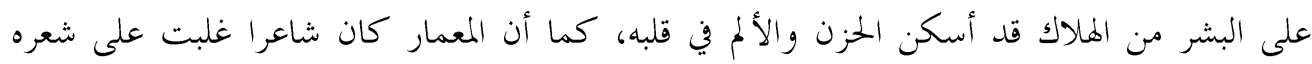

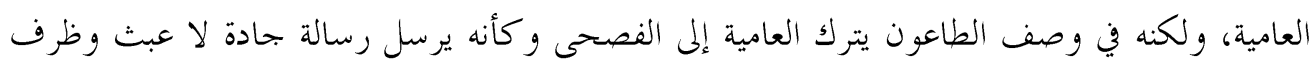
وبحون فيها، ويريد لها الخلود و بلوغ كل عربي ولا تبقى في نطاق بحتمعه الضيق.

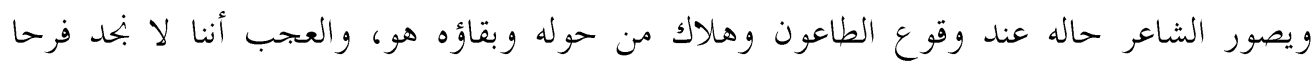

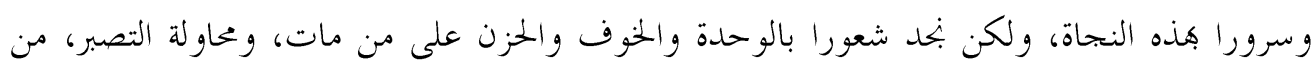

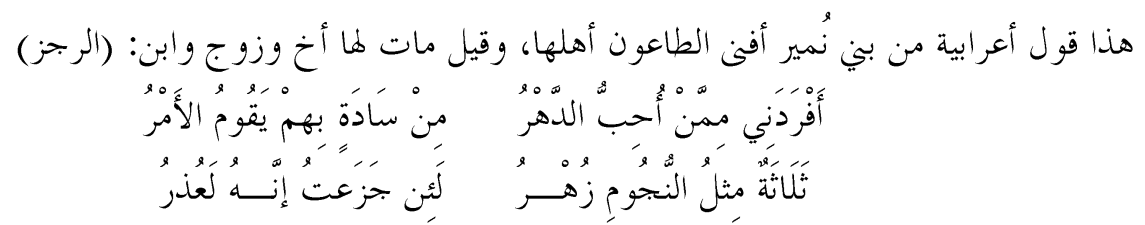

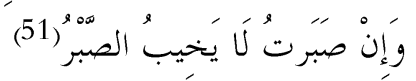

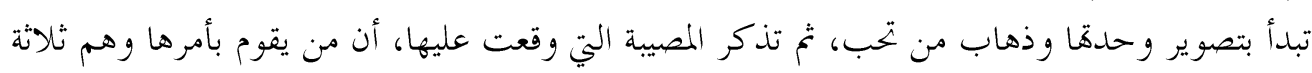

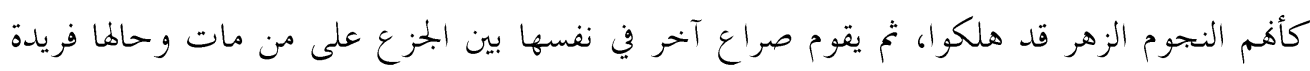

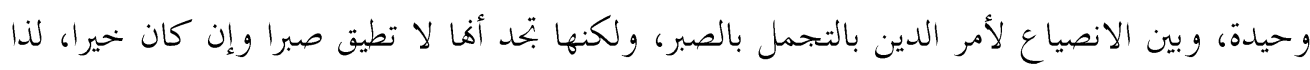

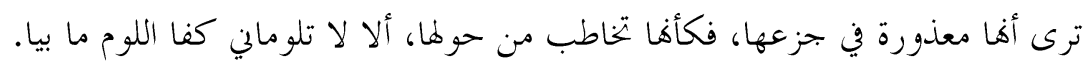


ومن الشعراء الذين كثر شعرهم في الطاعون ابن الوردي، وقد مات فيه سنة (749ه)، "وَيقَال إن هَذَا

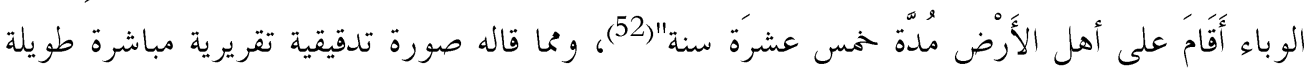
ينظر نظرة عالم متمرس في الإنسان وطباعه والحياة وتقلبها، فأخذ يصف اضطراب الناس وتقلب

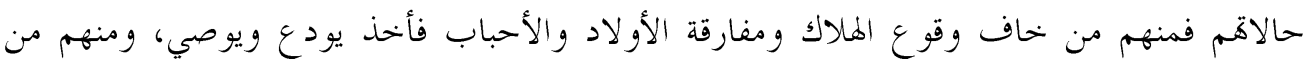
يحاول تنقية أشغاله وتبيان ما له وما عليه، وآخر يعد أكفانه، وترى الصور تدل على على إقبال الناس على ولى

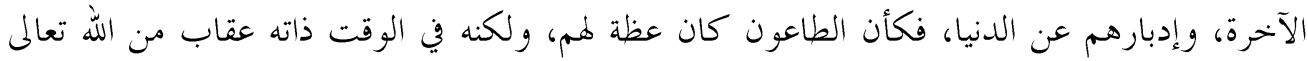

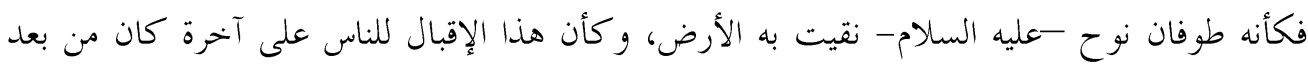

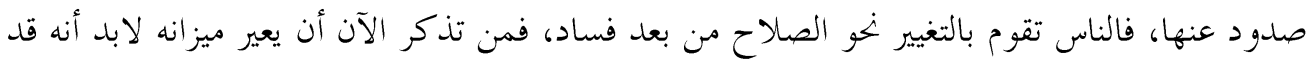

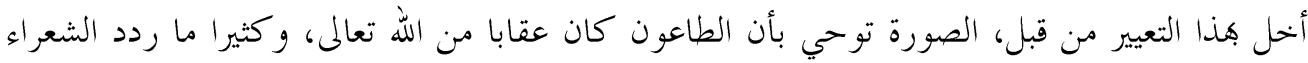

$$
\text { هذه الصورة، قال: (المتقارب) }
$$
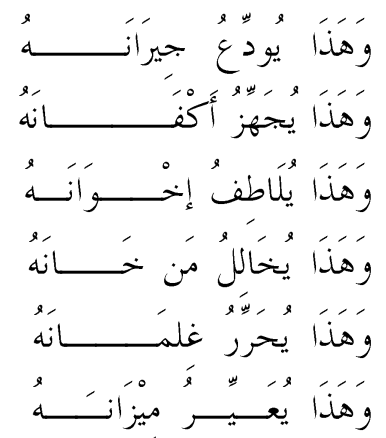

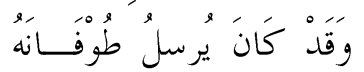

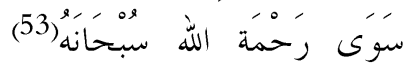
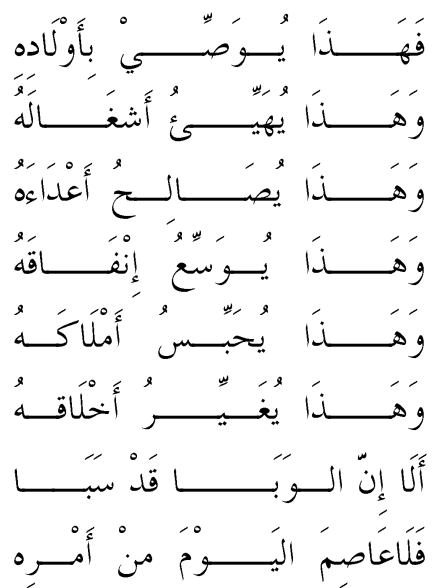

من الشعراء العلماء الذين كثر شعرهم في الطاعون ومات فيه صلاح الدين خليل بن أيبك الصفدي (ت

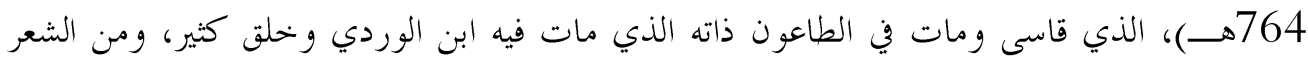

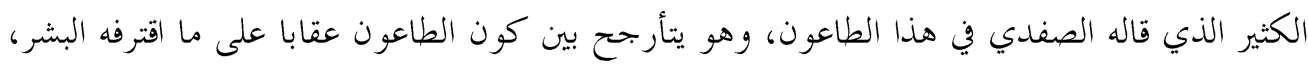

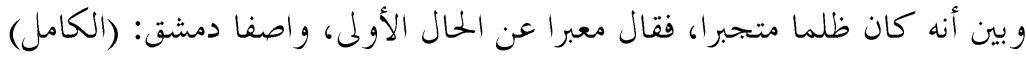

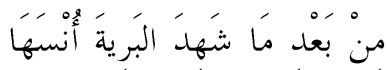

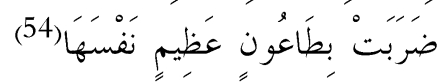

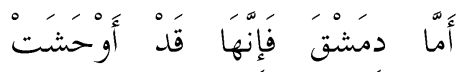

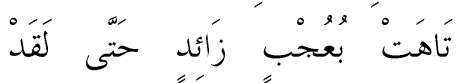


فدمشق قد تاهت وتعالت وتكبرت بعد علوها بين البشرية، فاستحقت الطاعون فيقول أها طعنت نفسها بفعالها، فكان جزاؤها الطاعون الذي أوحشها من أهلها، وأذهب أنسها ورفعتها، ولكنه يقول في بيتين آخرين مخاطبا الطاعون: (الكامل)

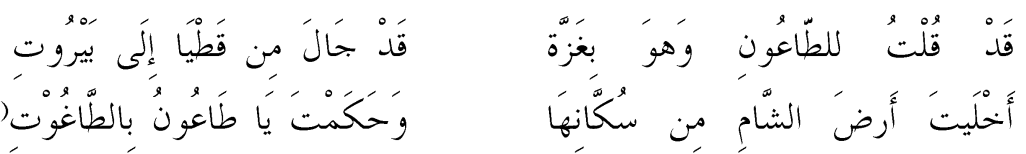
يشتص الصفلي الطاعون ويصوره فارسا قد جال جولته في بلاد الشام فأباد أهلها و كأها ساحة معركة يفتك فيها الطاعون بأعدائه، ثم بعد ذلك يذكر مقول القول، أنك يا طاعون حكمت بالظلم و لم تنصف الناس، فكأن الطاعون قد عم عقابه الصالح والطالح، فعند النظر في هذا النص والذي سبقه بهد الشاعر مرة يرى الناس استحقوا الطاعون بفعالهم، وفي الثانية يرى أن الطاعون قد ظلم وطغى، وهذا يصور اضطراب الشاعر، بل إن الشاعر نفسه يصور اضطراب الناس في نص ثالث، إذ قال: (الكامل)

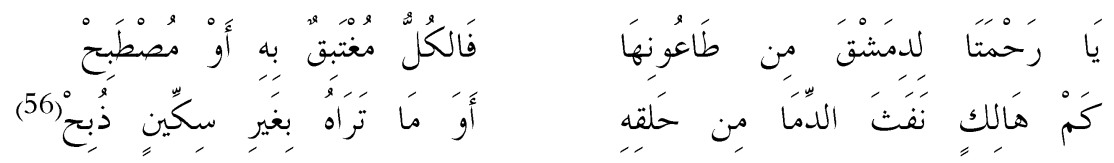
هنا يلعو بالرحمة للدشق من طاعوها، ثم يصور الناس و كأفم سكارى ما بين من احتسى الخمرة صباحا

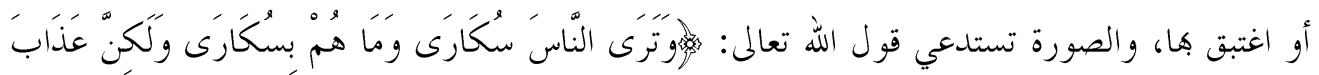

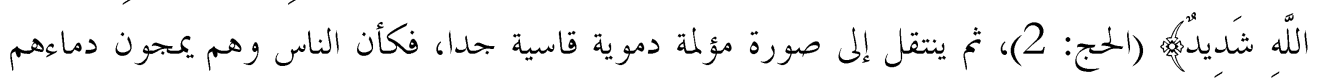
ذبكوا بغير سكين، فالشاعر ومن حوله كلهم في حال اضطراب وانفعال، ولعل محا يلاحظ على نصوص الصفدي أها جاءت على الكامل هذا البحر الذي يميل إلى الشدة(57)، وأكثر فيه من تسكين ثانيه (الإضمار) الذي يهيلها مستفعلن فيقربه من الرجز الانفعالي المضطرب(58). ولعل من النصوص الغريبة التي صورت الطاعون قول الصفلدي كذلك: (الرمل)

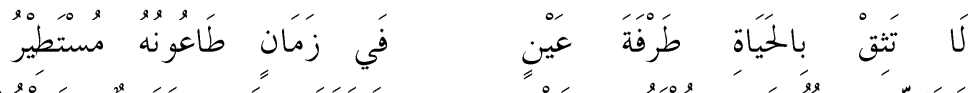

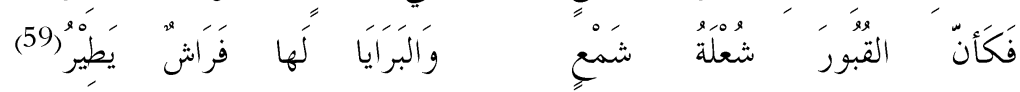
هل طفى طلب الشهادة بالطاعون على البشر حد أن أصبحت القبور كأفا النور، وهم كالفراش ينجذب إليه مذهو لا منقادا بغريزته في حب الضوء، هل أحبوا الآخرة هذا الخب؟ لا أعتقد أن هذا الوصف أو التفسير للبيت يمكن تعميمه على المجتمع، فليس من بحتمع يصد هذا الصدود عن الدنيا، وهو ذاته يوصف بأنه عوقب لإقباله عليها، ولكن قد يريد الشاعر كثرة الموتى، 
وسلبهم للإرادة، وإن كان كل بشر يلقى الموت مسلو ب الإرادة، فلا أعتقد أن الشاعر أحسن في تصوير

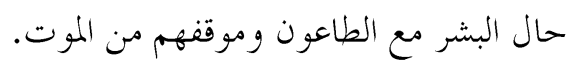

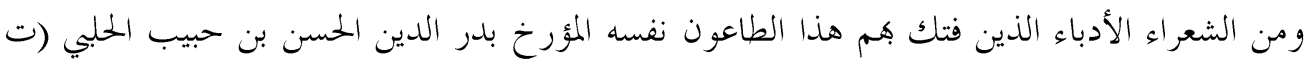

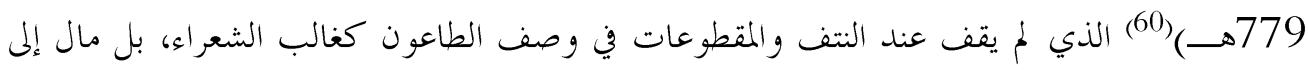
القصيد، هذا التوسع الذي نتج عن تقليبه المعاني والتنقل بين وصف هذا الوباء نفسه، ووصف حال

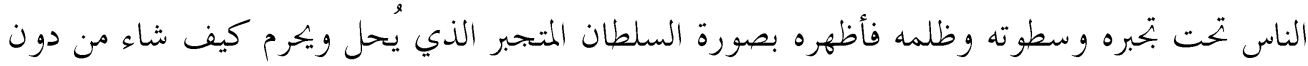

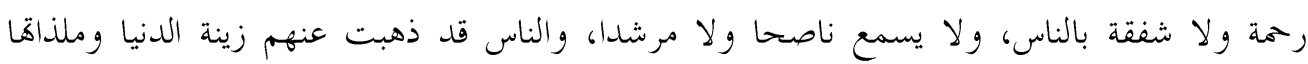

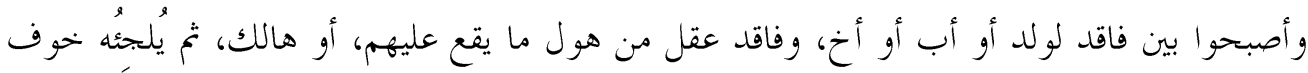

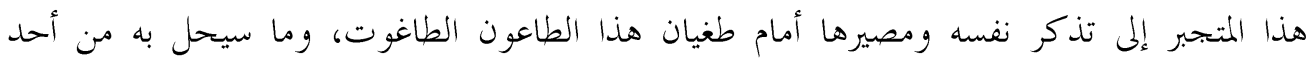

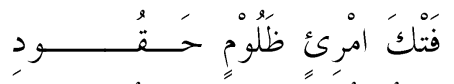

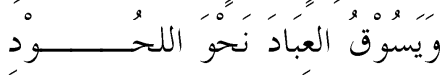



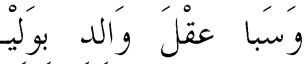

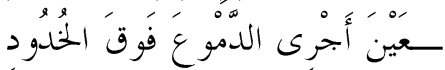

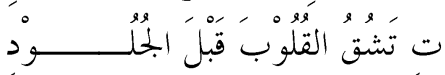

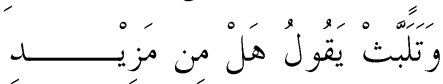

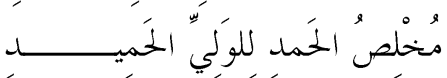

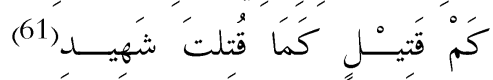
الأمرين و كلاهما حبب عنده قال : (الخفيف)

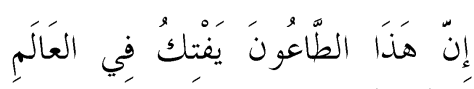

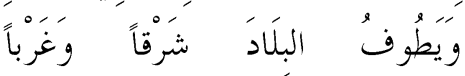

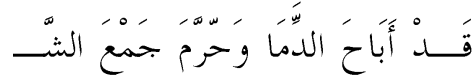

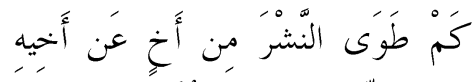

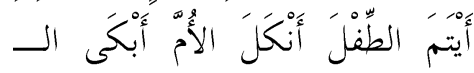

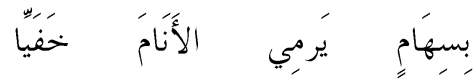

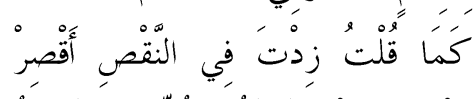

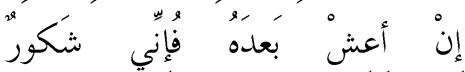

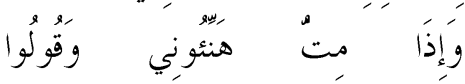
و يبلو الثاعر جمال اللين محمد بن نباتة المصري ساعيا إلى طلب الدنيا و حبها وخوف الممات عند الناس بلغ أن يخالفوا أوامر الرسول محمد صلى الله عليه وسلم للمسلمين بأن لا يغادروا بلدا فشا فيه الطاعون ولا يدخلوه(62)، فقال متحدثا عن الطاعون نفسه أصاب دمشق، ورلكنه يغادرها فقد أذهب الطاعب الطاعون جمال دمشق ولذها، وكثل الموت فيه ورخص حتى أصبحت النفس تعدل حبة: (الخفيف) بلهن

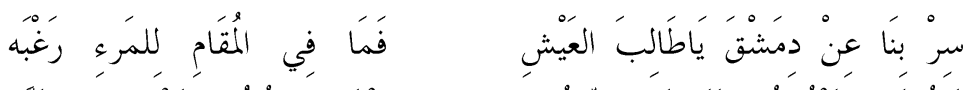

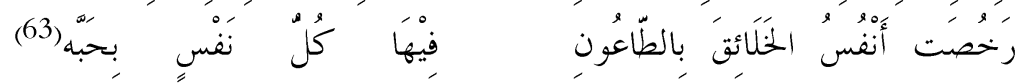
النصوص السالفة تمثل أغلب ما عالجه الشعراء وهم يقفون مذهولين أمام هول الطاعون 


\section{المبحث الثاين: أغر اض ومعان تتعلق بالطاعون:}

لم يقتصر الشاعر على وصف الطاعون ذاته، ولكنه تعداه إلى أغراض ومعان عدة تنبع من خلال معاناته في تجر بته مع هذا المرض الفتاك، فضلا عما تختزنه ثقافته ونظرته للطاعون، ومن هذا:

\section{رثاء الأحباب:}

ولعل المعاناة الثانية التي يو اجهها الشاعر بسبب الطاعون هي فقد أحبابه، ومن الشعراء من بكى أبناءه أو أو أوناء

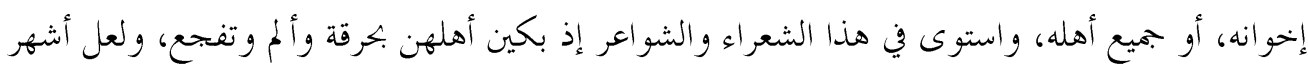
نص في هذا قصيدة لأبي ذؤيب الهذلي (ت 27هـهـ) الذي كان لهونه له عشرون ابنا وبنتا فزوجهم، فصار له

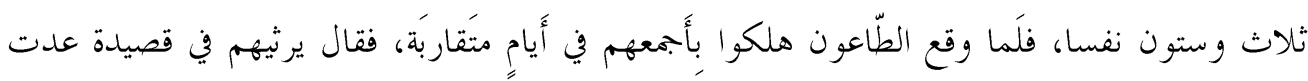

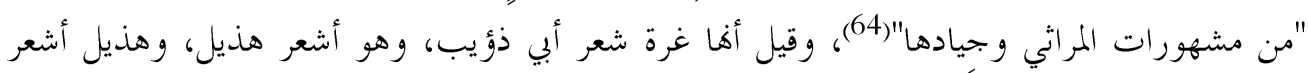

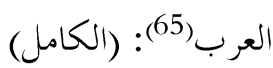

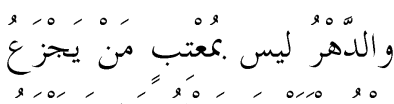

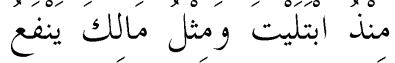

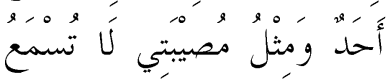

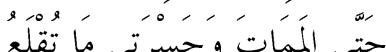

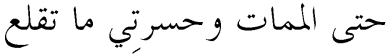

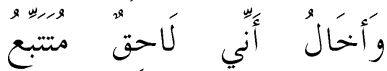

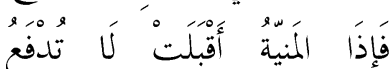

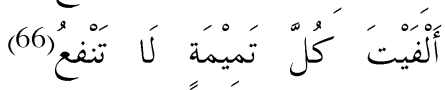

أَّنَ

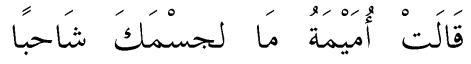

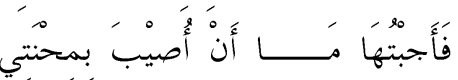

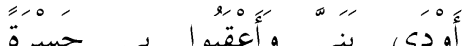

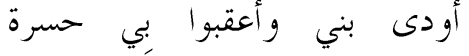

فَغبرته

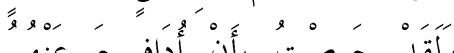

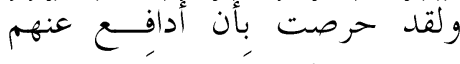

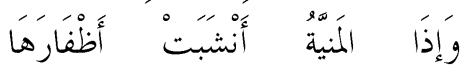

شخصية الهذلي تقف بين أمرين بين التعقل والتصبر من جهة، وألم المفجيعة وفقدان الأبناء والأحفاد من

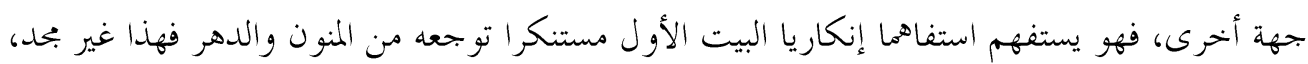

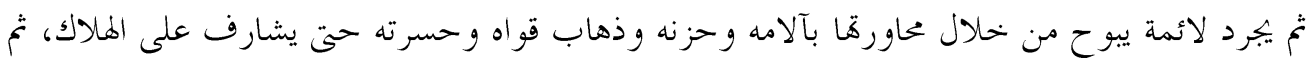

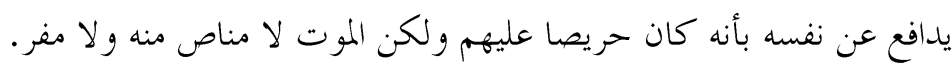

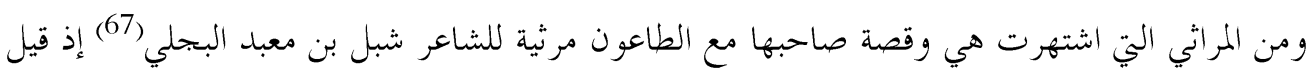

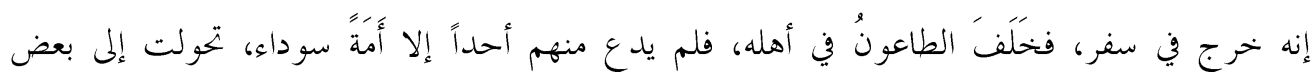

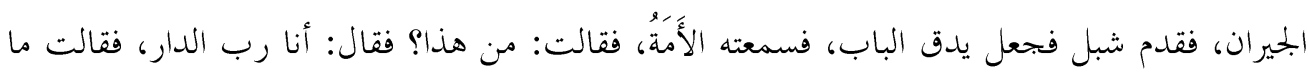

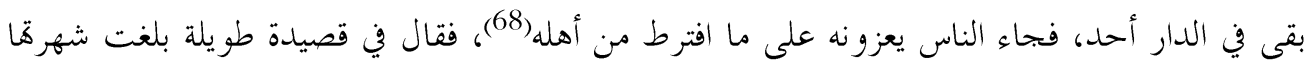


حتى دعيت لعدد من الشعراء(69)، و يرى أبو هلال العسكري أن ليس للعرب مرثية أجود منها(70):

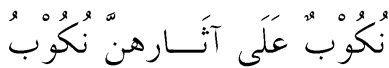

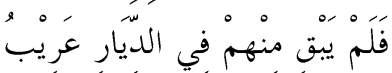

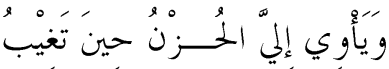

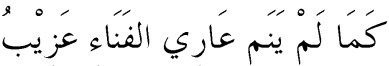

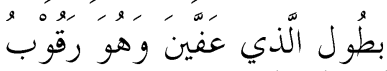

وليس له في الغابرين حبيب؟ٌ

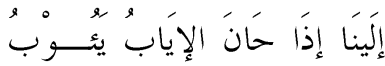

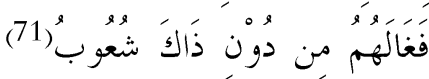

(الطويل) - - (ال)

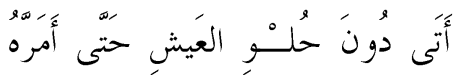

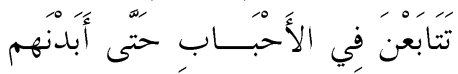

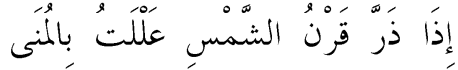

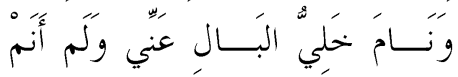

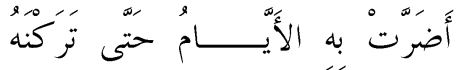

وكيــف بقاء المرء من بعد أهله

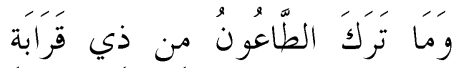

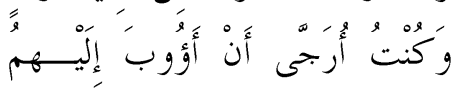

قصيدة تفيض ألما وحزنا، فالشاعر يحاول أن يتخلص من آلامه و حزن بالأماني، ولكنها سرعان ما تخيب، تم يستسلم بأنه لا يستطيع البقاء بعد أهله الذين أفناهم الطاعون، فيبدو الشاعر منهار القوى لا يستطيع أن يفكر ويتدبر كالهذلي، فقد غلبه الحزن وألم الفقد.

"وقال عكرشة بن أربد العبسي(72)، و كان قد خرج إلى الشام فهلك بنوه بالطاعون: (الطويل)

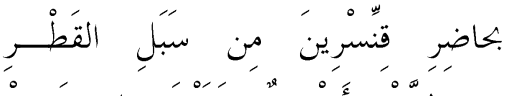

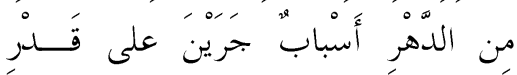

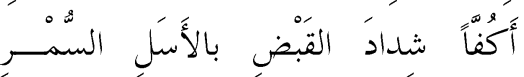

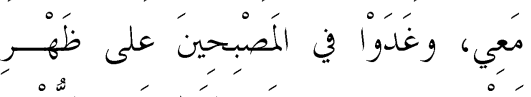

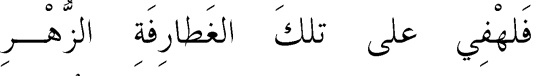

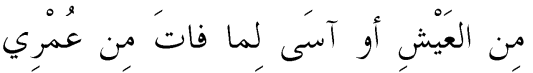

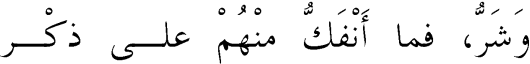

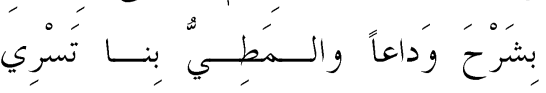

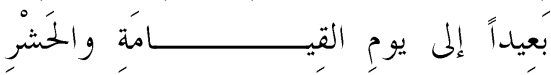

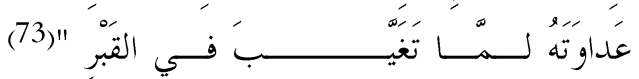

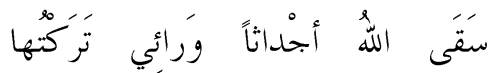

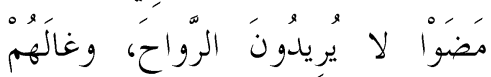

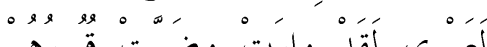

لَعمري لَّد وارت وَته وضمت قبورهم

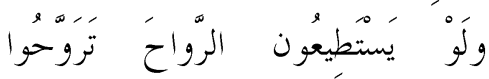

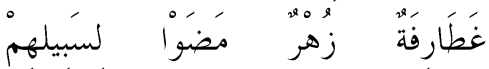

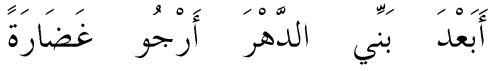

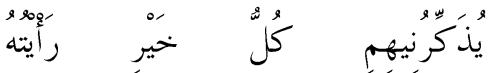

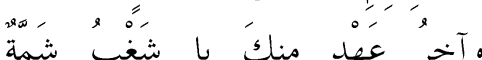

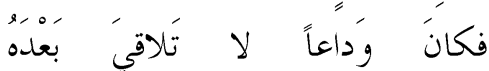

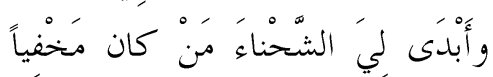


يفقد عكرشة أبناءه فقد فرسان شجعان يراهم نصرا عند الشر وعونا على الخير، فتظهر روح الصراع

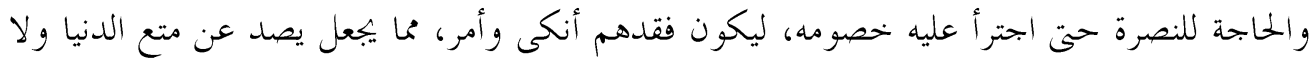
يأسى لوقائعها. ثلاث بتحارب كل واحدة منها عبرت بصدق عن صاحبها وحياته وتفكيره، والشعراء ثلاثتهم استعانوا بشيء من السرد و كأفم يماولون تخفيفا عما يعانونه ببث لو اعجهم وآلامهم، فاستعانوا ببحرين واسعين

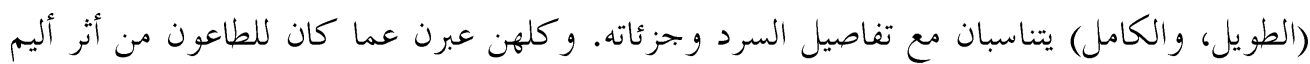
في الإنسان العربي، ولكنه أنطقه بمراثي عد بعضها من أعذب المراثي في الشعر العربي القديم، إذ عانى

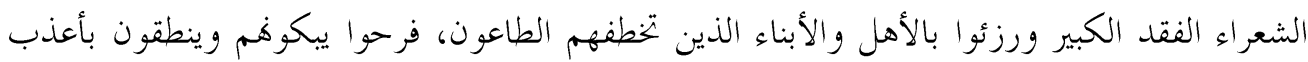

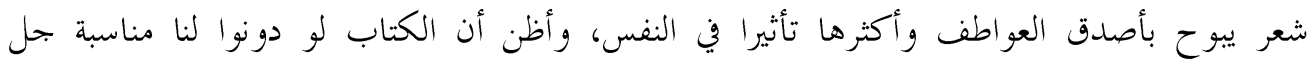
القصائد لوجدنا من المراثي الكثير التي كانت نتاج فتك الطاعون بالعرب.

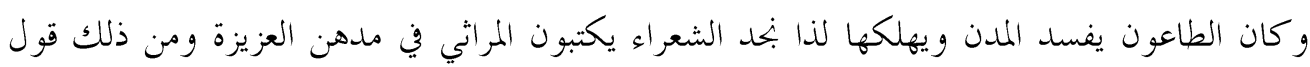

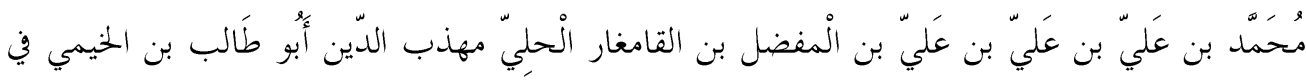

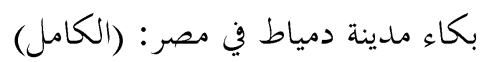
ووَجدت وجدات الفاقد المحزون

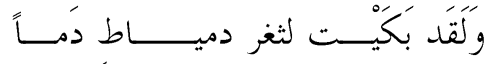

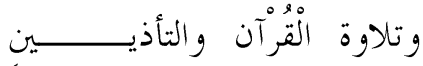

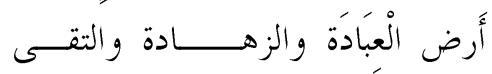

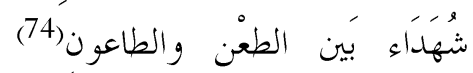

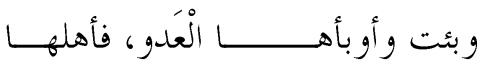

والحديث في الرثاء الأهل والأحباب والأصحاب بسبب الطاعون يطول، ولكنا نكتفي هذذا لضيق الوقت.

\section{التسليم لقضاء الله، و الصبر:}

ندر أن وصلنا شعر عن الطاعون من فترة ما قبل الإسلام، لذا ظهر أثر الإسلام جليا وواضحا في المواقف من هذا المرض، ومن تلك المو اقف التي تكررت كثيرا عند الشعر اء لدى وقوع الطاعون التسليم والانقياد

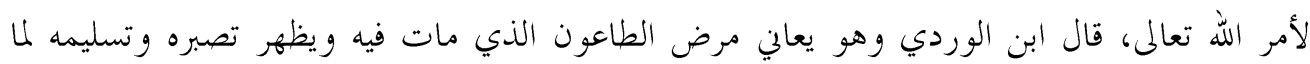
يقضيه الله تعالى فيه: (الوافر)

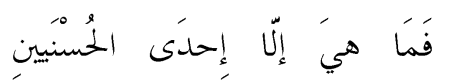

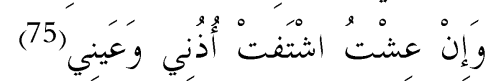

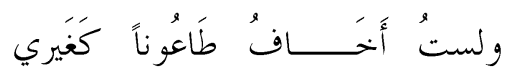

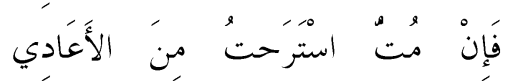


ويلاحظ على البيتين أن ابن الوردي كأنه يدعو بالهلاك على أعدائه إذا بقي حيا فإن أذنه وعينه

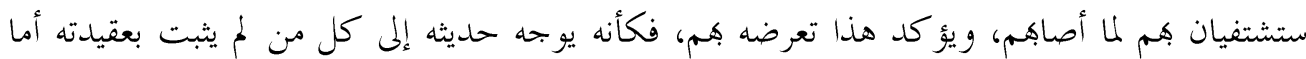

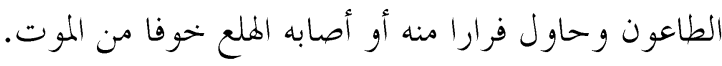

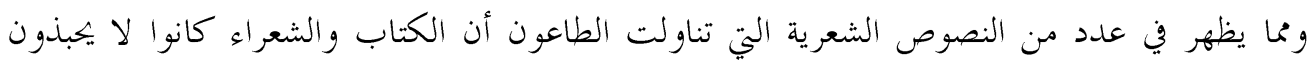

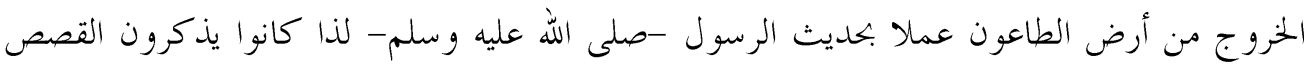
الفاشلة لتلك المحاولات، ويتبين من شعرهم عدم الرضا، بل ترى اللوم وربما التعريض، على الرغم من

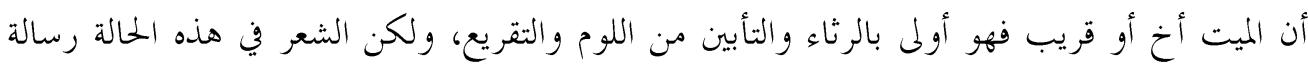

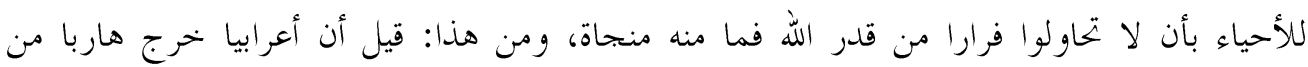
الطاعون فلدغته أفعى في طريقه فمات. فقال أخوه يرثيه: (مشطور المديد)

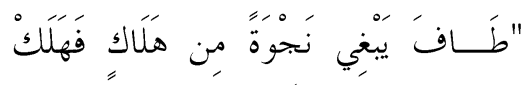

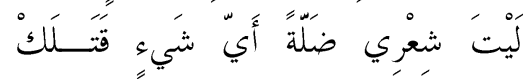

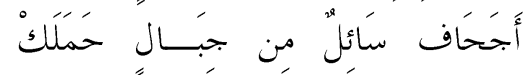

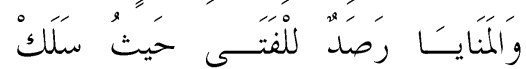

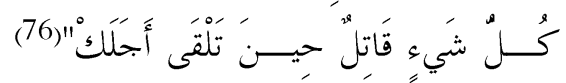

وروى الأصمعي (ت 215هـ) قال: هرب أحد أهل البصرة من الطاعون فركب على حمار له ومضى تهى

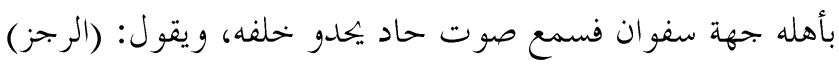

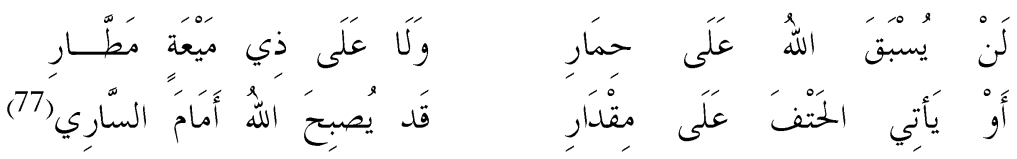
و الثبات والبقاء في أرض الطاعون مفخرة لأنه الصبر والتسليم لقدر الله وأمره قال إبراهيم بن علي بن بهن

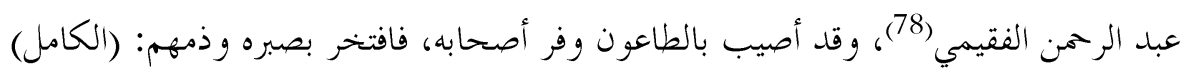

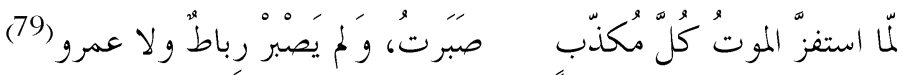

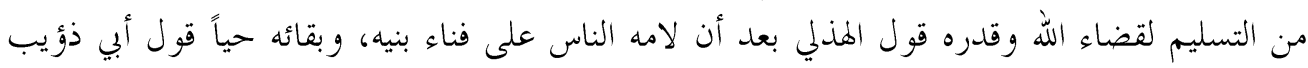

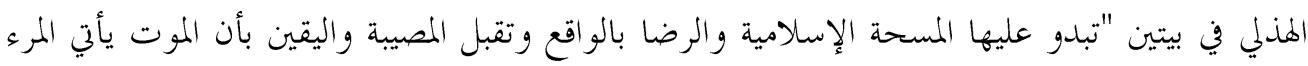
ولو كان في بروج مشيدة"(80) إذ قال: (الطويل)

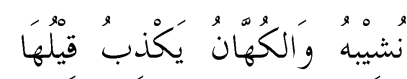

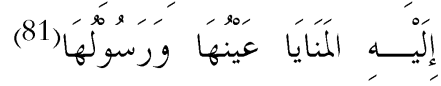

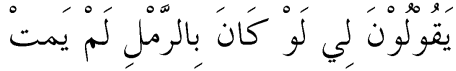

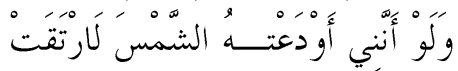


ومن الأبيات الظريفة في التسليم لقضاء الله والصبر على مصيبة الطاعون، قول الشاب الظرف محدثا خله متلاطفا معه: (الطويل)

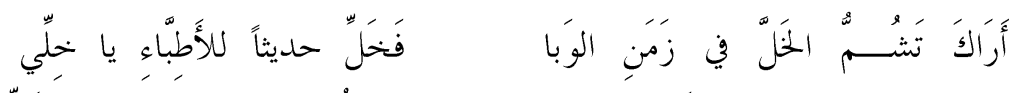

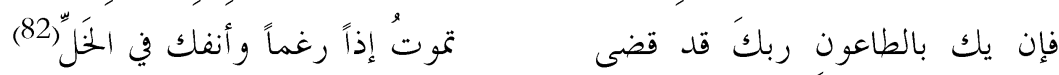

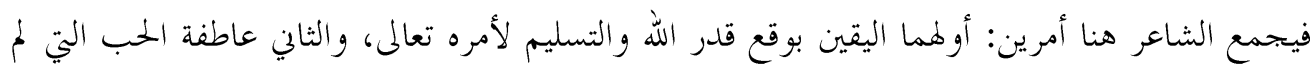
تمنع أن يعابث حبيبه ويلاطفه ولو كان محاطا بالطاعون.

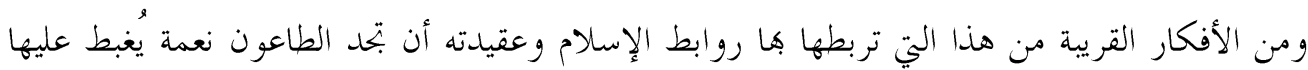

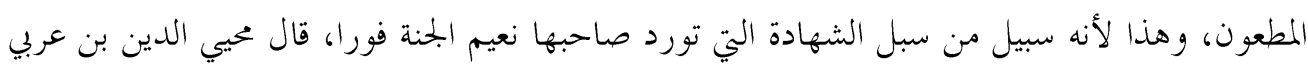

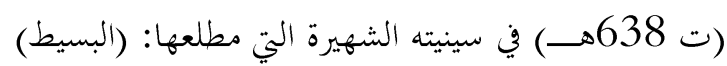

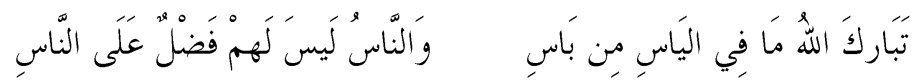

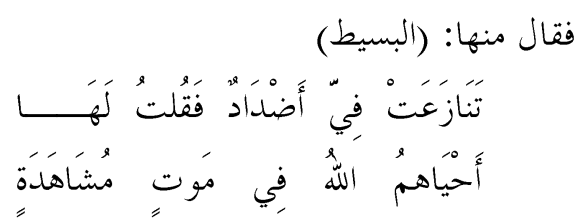

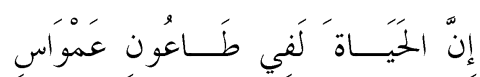

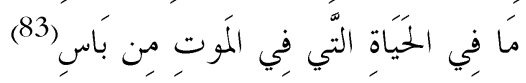

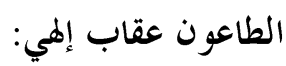

رأى بعض الشعراء الطاعون عقاباً يصبه الله تعالى على المفسدين خاصتهم وعامتهم، وأنه جعله مهلكة

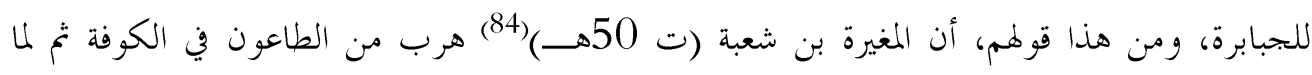

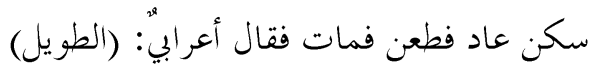

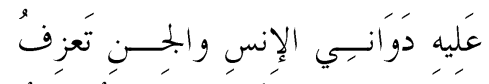

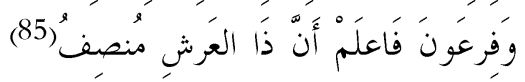

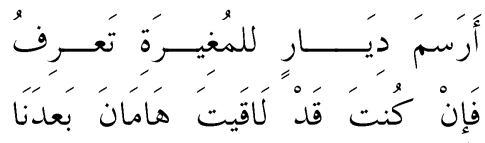

يرى هذا الأعرابي المغيرة من الطغاة الظالمين، ففرح بإصابته بالطاعون موته، و كأن الطاعون كان له

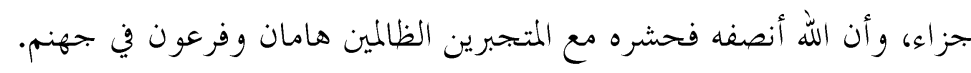

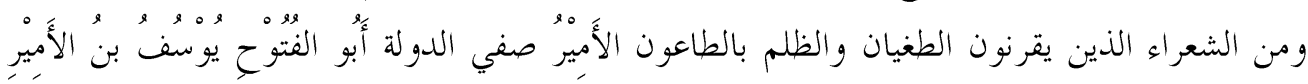

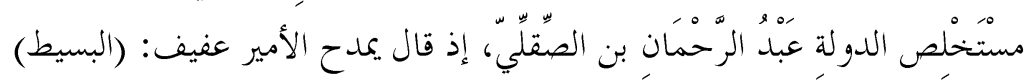

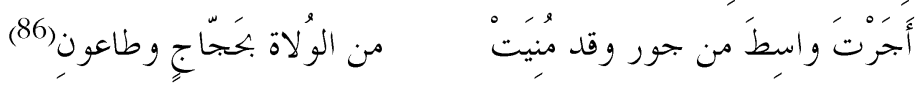

وخرج الشاعر حمزة بن بيض (116هــ) (87) "يريد سفرا فاضطره الليل إلى قرية عامرة كثيرة الأهل

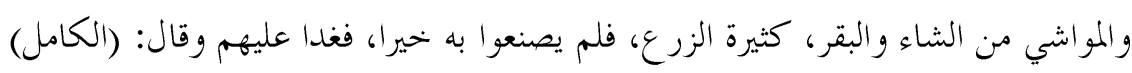




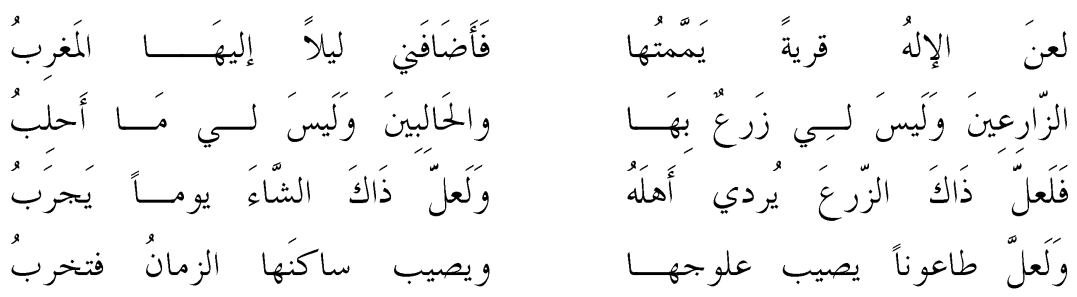

فلم يمرّ بتلك القرية سنة حتى أصاهـم الطاعون فباد أهلها وخربت"(88). لم ير ابن الرومي الطاعون عقابا إلهيا، بل رآه وسيلة من وسائل الدهر الكثيرة والقبيحة في عقاب و إفناء بين البشر، وعلى ما يصبه الطاعون من آلام ومصائب على الإنسان فهو ليس أقبح أفاعيل الدهر، بل هو يستخدمه إن عف، فقال: (البسيط)

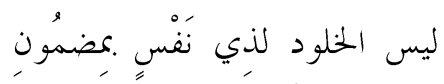

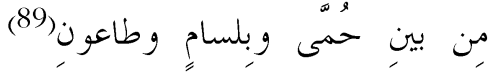

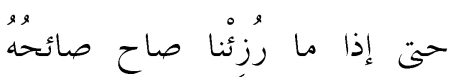

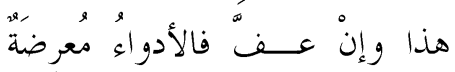

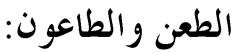

ومن الفترات العسيرة على الأمة الإسلامية ما ابتلاها الله بجمع الأوبئة والحروب عليهم، فيكون المسلمون

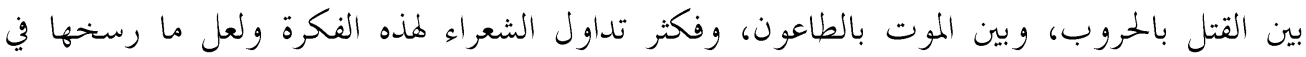

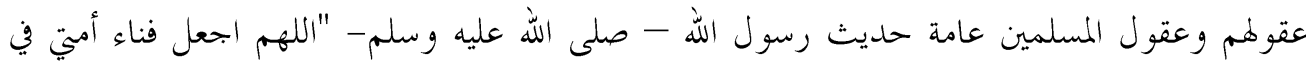

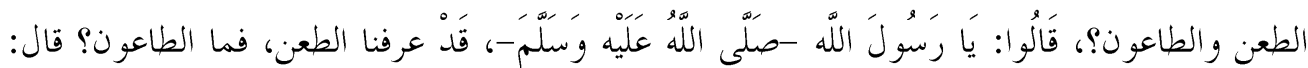

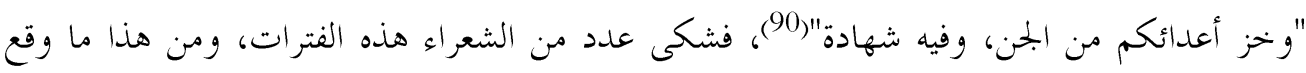

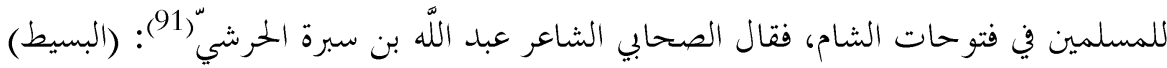

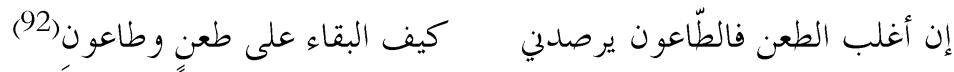

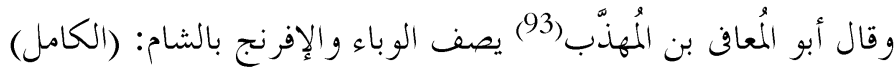

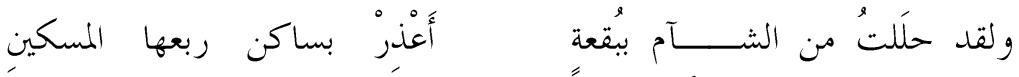

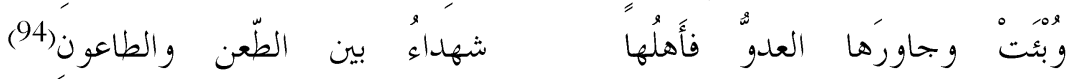

وجعلت أرض الشآم جامعا للطعن والطاعون بل قيل أن "من خواصها الطاءات الثلاث: الطعن

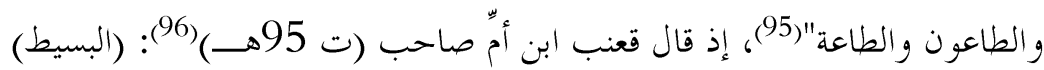

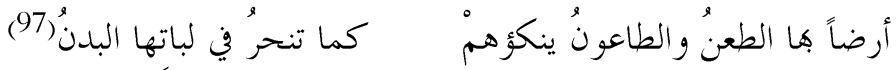


و لم يكن الطعن و الطاعون يجتمعان في كل الأحوال، فربما كانا ناصرين للمسلمين كيوم غزا التتار بلاد الشام أصاهم الطاعون و اهزموا في معارك عديدة، قال شريف الدين عبد العزيز الأنصاري شيخ الشيوخ

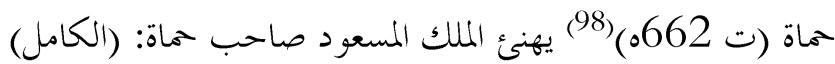

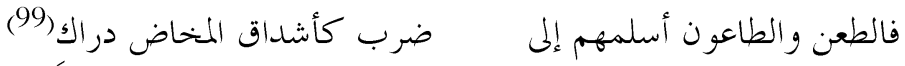

\section{توظيف الطاعون في الصورة الفنية:}

قد يعجب قارئ أن يجد توظيفا لصورة الطاعون في الهجاء الفكاهي، ولكن خيال الشعراء وتصوراهم تقرب البعيد وتبعد القريب، وليس ها حدود تحول دون إتياها بالغريب، ولقد حظيت الفكاهة بعناية

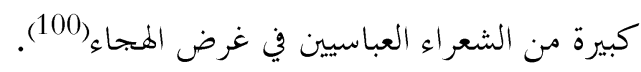

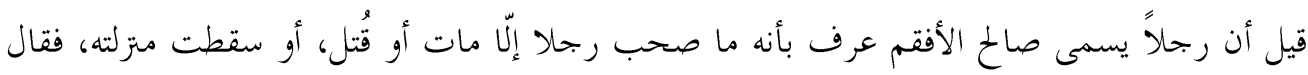

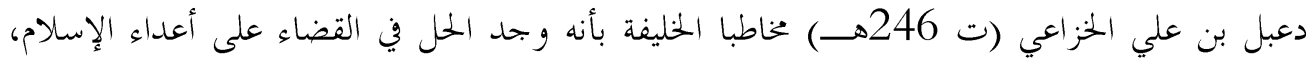
فقال: (الكامل)

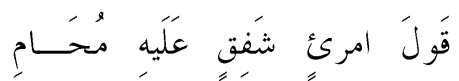

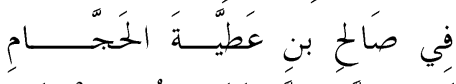

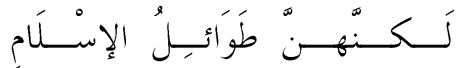

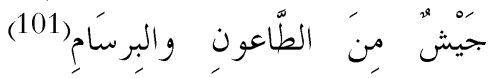

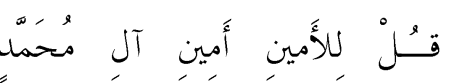

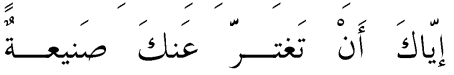

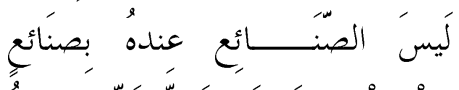

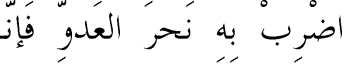

سخرية دعبل قامت على المبالغة والغلو وهذا من أكثر أساليب السخرية استخداما في الشعر لئر

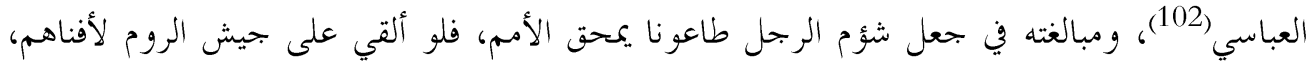

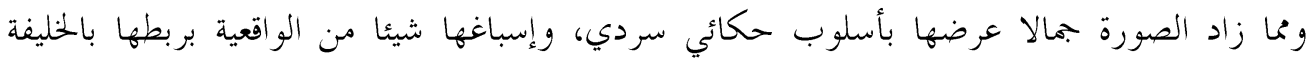
المأمون، إذ أجاد دعبل هذا الهوره الهجاء الساخر وأحسن في تصويره. وقال شاعرّ آخر في هجاء رجل: (بحزوء الو افر)

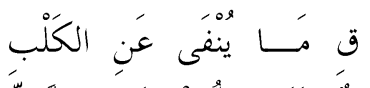

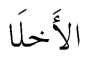

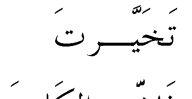

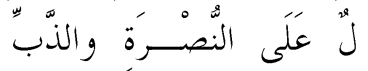

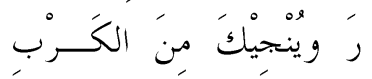

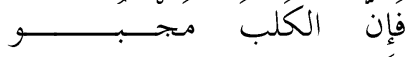

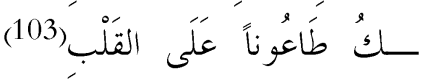

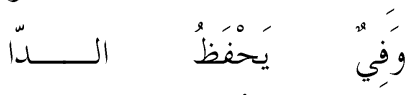
فَلَو أَشْبهته

إذا كان دعبل قد سخر من نحس وشؤم صاحبه، فإن هذا الشاعر يسخر من جبن وغندر وخذلان

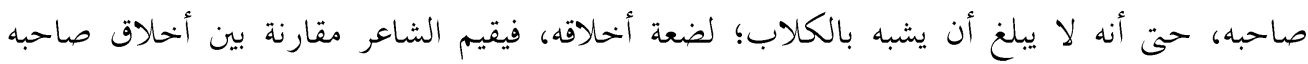


وأخلاق الكلاب، ويخلص إلى أن صاحبه لم يشبه الكلام في محامدها، ولأنه لم يشبه الكلاب صار

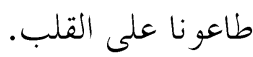
وقال أبو تمام حبيب بن أوس الطائي (ت 231هـــ) مادحاً القائد الأفشين(104) ويصف شدته وشجاعته

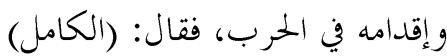

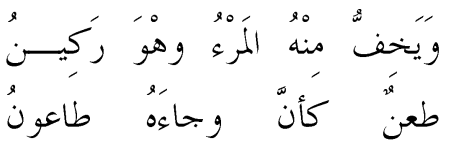

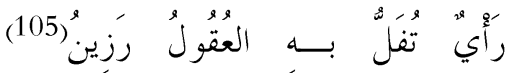

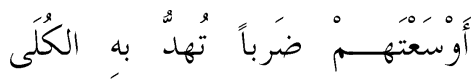

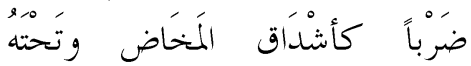

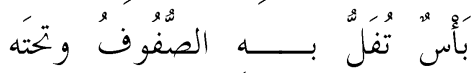

يصور أبو تمام قوة الأفشين وضربه وطعنه، فشبه طعنته كأنه الطاعون الذي لا يرجى برؤه.

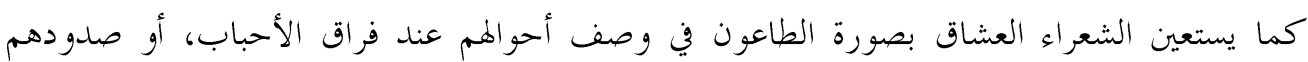
عنهم، ومن هذا قول جران العود النمري: (البسيط)

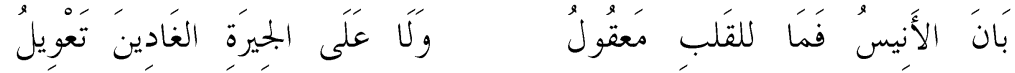

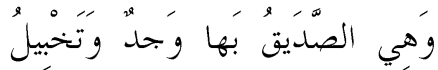

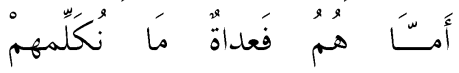

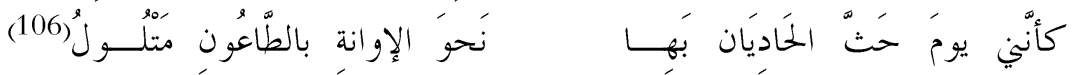
يصور جران العود حاله يوم هم أهل حبيبته بالرحيل عنهم والفراق، فيشبه ما يقاسيه من آلام ويعانيه من ضعف وسقم .كمن أصابه الطاعون. ومن الصور التي كثرت عند المتغزلين يصفون حال سقمهم ووجدهنم ما يمكن أن تحمل على معنيين؛

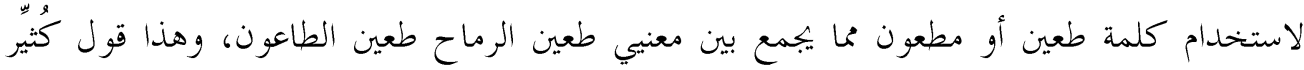
عزة: (الطويل)

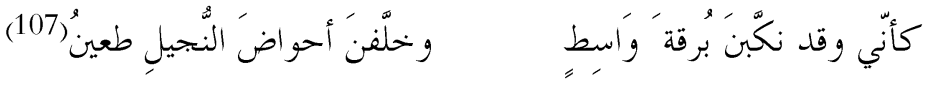

$$
\begin{aligned}
& \text { ومثله عمر ابن أبي ربيعة: (الوافر) }
\end{aligned}
$$

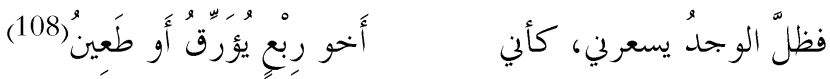

فهل أرادا طعين أي أصابه الطاعون، أم أرادا من طعن برمح أو حربة، وأرى أن المعنيين يصلحان هنا،

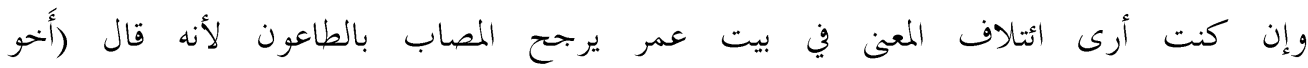

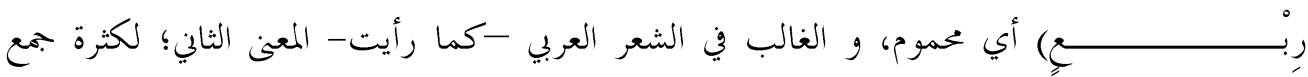
طعين مع الضرب، والقد الذي يشبه عادة بالرمح. 
و لم يقف استخدام شعراء الغزل لصورة الطاعون على وصف حالهم ومعاناقم، بل بند من أقدم الصورة صورة الشاعر العذري عروة بن حزام وهو يدعو على الحاديين لتفرقهما بينه وبين حبيبته عفراء بأن يصابا بالطاعون، فقال: (الطويل)

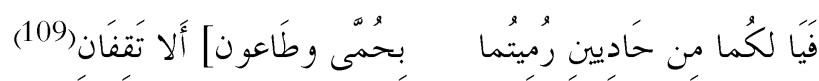
وتوظيف الطاعون في الصورة كثير، خاصة عند الشعراء في غزلياهم.

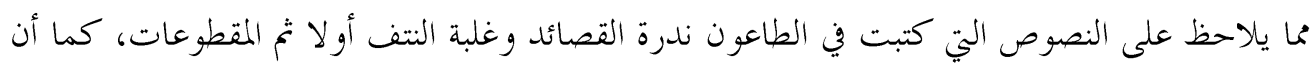
أساليب البيان قد قلت كذلك، وساد على الشعر الخطاب المباشر، فضلا عن ندرة أساليب البديع،

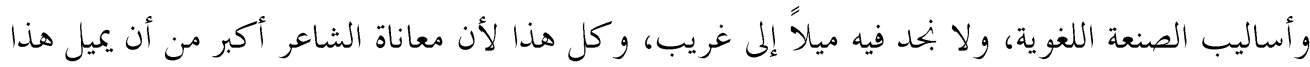

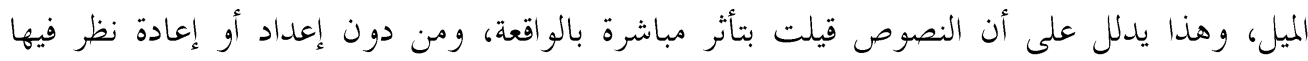
وتنقيح لها، فتحمل شعورا صادقا وبتربة حية.

الحخاتمة:

كثرة تفشي الطاعون في بلاد العرب وشدة خوفهم وهلعهم منه وشعورهم بالعجز أمام بطشه فنسبوه إلى

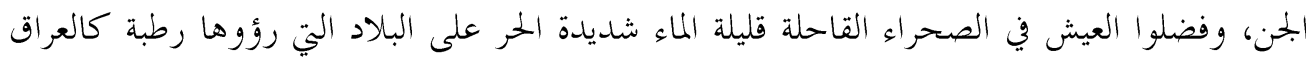
وبلاد الشام فرارا منه لاعتقادهم أنه يكثر في تلك البلاد سيما بلاد الشام، وقد كثرة أسماؤه لديهم.

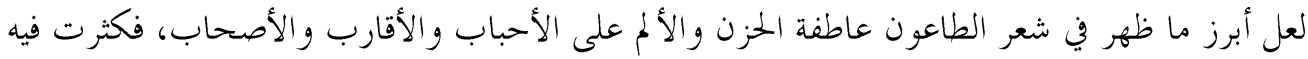
المراثي، وقيلت بسببه عدد من أشهر مراثي العرب، وأشهرها مرثية أبي ذؤيب الهذلي في أبنائه، كما أن

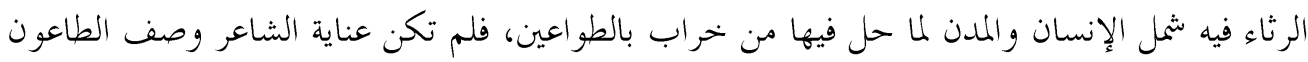
بل ما يخلفه من دمار للمدن و إفناء للبشر. يكاد أن يكون كل ما وصلنا من الشعر الذي قيل بسبب الطاعون قيل بعد ظهور الإسلام؛ لذا ظهور

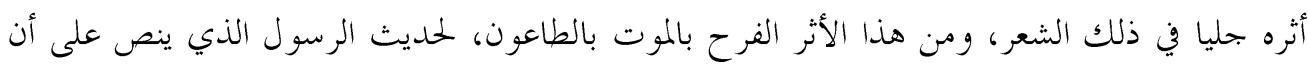

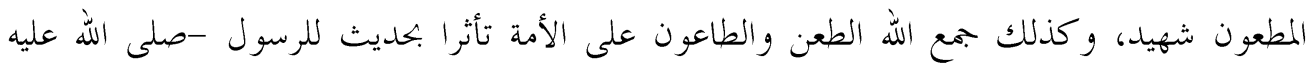
وسلم، و كذلك ورفضهم لفكرة الخروج من البلد الموبوء تأثرا بحديث آخر للرسول -صلى ولى الله عليه

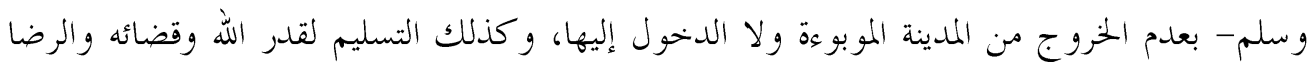

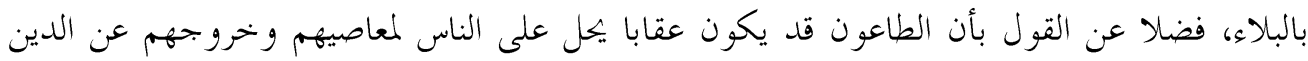
وتعاليهم. 
جل النصوص الشعرية التي وقفنا عليها كانت تصف حالة الفقد والحزن، بجاه ما يفعله الطاعون من خراب وقتل، وندر أن بجد وصفا له، فالشاعر ركز على الجانب الوجداين في هذه المأساة. لو لا ما ورد إلينا من قصائد رثائية في بكاء الأحباب؛ لكانت النصوص القصيرة (المقطعات و النتف) هي الغالبة، فكثيرا ما جاءت النصوص التي تصف الطاعون متكونة من بيتين أو أربع بالكثير، فهي لمحات وصور جزئية تمر أمام الشاعر فيسجلها. استخدم الشعراء صورة الطاعون في التعبير عن آلام حبهم وغزلهم، وفي مهاجيهم الفكاهية الساخرة والجادة، وورصف بطشهم وقوة وشدة ممدو حيهم. ما قيل من شعر في وصف الطاعون جاء صادق المشاعر والأحاسيس، بعيدا عن الصنعة والتكلف، معبرا عن الألم في لحظة معاناته و الفجيعة آن وقوعها.

1. أبو ذؤيب الهلفي حياته وشعره، نورة الشملان، عمادة شؤون المكتبات/ جامعة الرياض، الرياض- المملكة العربية السعودية، 1980.

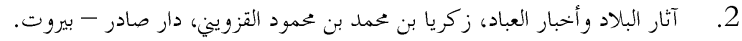

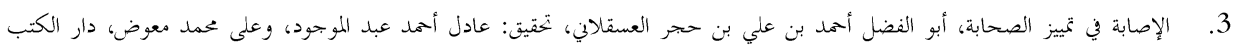

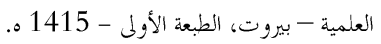
4 4. الأصدعيات اختيار الأصمعي أبو سعيد عبد الملك بن قريب بن علي بن أصمع، تحقيق: احمد محمد شاكر - عبد السلام محمد هارون، دار المعارف - مصر، الطبعة السابعة، 1993م.

5 5. الإعجاز والإيجاز، أبو منصور عبد الملك عبد الملك بن محمد بن إسماعيل الثعالبي، دار الغصون، بيروت-لبنان، 1985، الطبعة الثالثة، 1985.

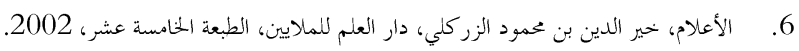

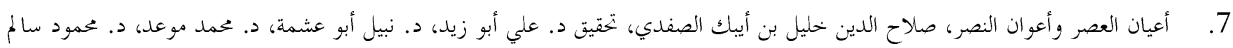

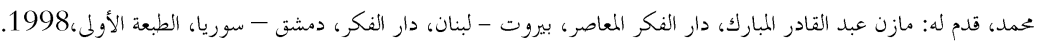
8. الأغاني، أبو الفرج الأصفهاني، تحقيق سمير جابر، دار الفكر، بيروت- لبنان، الطبعة الثانية.

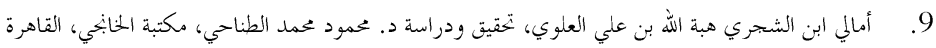

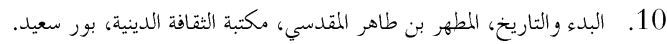
11. بذل الماعون في فضل الطاعون، ابن حجر العسقلاني، تحقيق: أحمد عصام عبد القادر الكاتب، دار العاصمة، الرياض.

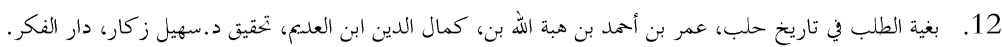
13 13. بغية الوعاة في طبقات اللغوين والنحاة، عبد الرحمن بن أبي بكر، جالال الدين السيوطي، تحقيق محمد أبو الفضل إبراهيم، المكتبة العصرية -

لبنان.

14. بلاغات النساء، أبو الفضل أحمد بن أبي طاهر، صححه وشرحه أحمد الألفي، مطبعة مدرسة والدة عباس الأول، القاهرة، 1908.

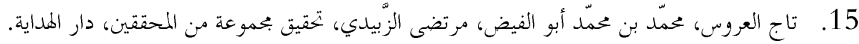

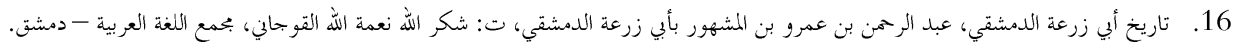

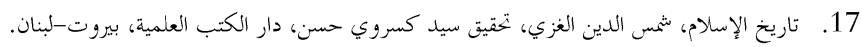
18. تاريخ مدينة دمشق وذكر فضلها وتسمية من حلها من الأماثل، أبي القاسم علي بن الحسن ابن هبة الله بن عبد الله الشافعي، تحقيق محب الدين

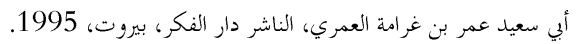

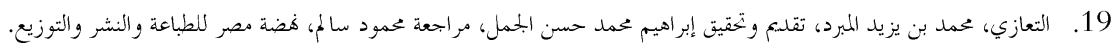
20. مذيب الكمال، يوسف بن الزكي أبو الحجاج المزي، مؤسسة الرسالة - بيروت، الطبعة الأولى 1980. 
21. مَذيب اللغة، محمد بن أحمد بن الأزهري المروي، تحفيق محمد عوض مرعب، دار إحياء التراث العربي - بيروت، الطبعة: الأولى، 2001م.

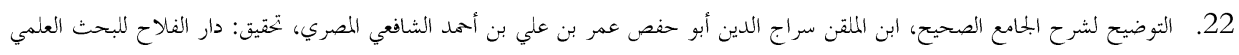

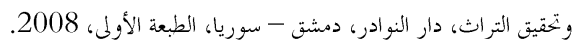

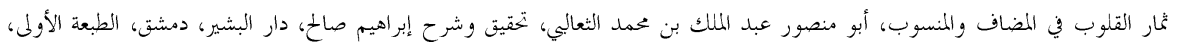

1994

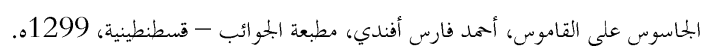

جمهرة أشعار العرب، أبو زيد محمد بن أبي الخطاب القرشي، حققه وضبطه وزاد في شرحه علي محمد البجادي، ذضضة مصر كلطباعة والنشر

والتوزيع.

26. همهرة اللغة، أبو بكر محمد بن الحسن بن دريد الأزدي، تحقيق رمزي منير بعلبكي، دار العلم للملايين - بيروت، الطبعة الأولى، 1987.

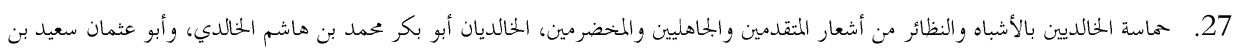

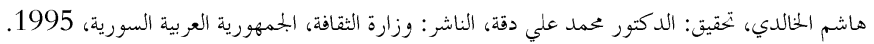

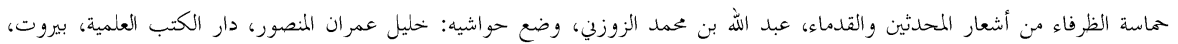

2001

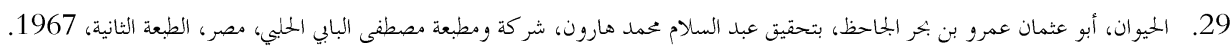

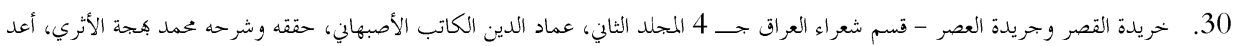

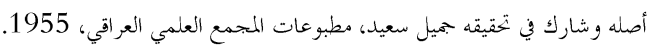
31. الدر الفريد وبيت القصيد، محمد بن أيدمر المستعصمي، تمقيق الدكتور كامل سلمان الجبوري، دار الكتب العلمية، بيروت - لبنان، ط1 المكا،

2015

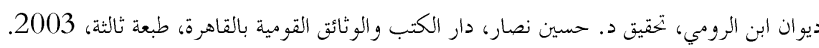

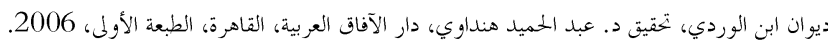
.32

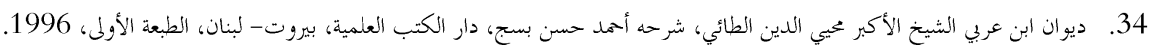

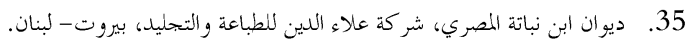

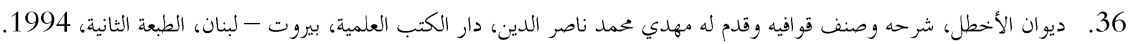

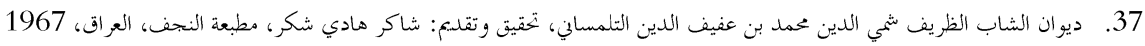

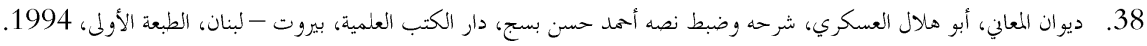

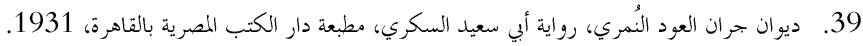

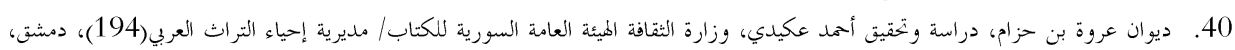

2014

ديوان عمر بن أبي ربيعة، قدم له ووضع هوامشه وفهارسه د. فايز محمد، دار الكتاب العربي، بيروت، الطبعة الثانية، 1996.

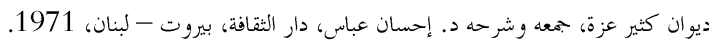
.41

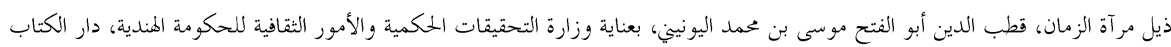

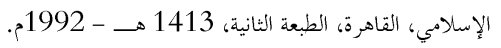

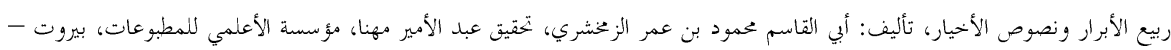

لبنان، ط1، 1992.

" رسائل الخاحظ، عمرو بن بحر بن محبوب الكناني، أبو عثمان، الجاحظ، تحقيق وشرح عبد السلام محمد هارون، مكتبة الخانجي، القاهرة،

.1964

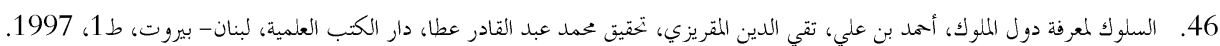

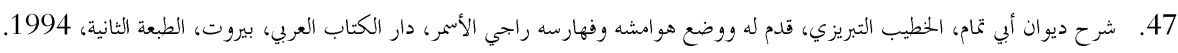

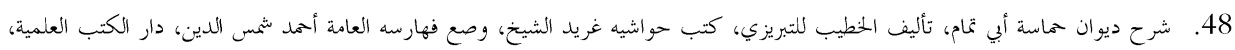

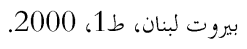

4. شعر دعبل بن علي الحزاعي، صنعة د.عبد الكريم الأشتر،مطبوعات بجمع اللغة العربية بدمشق، الطبعة الثانية، 1983. 


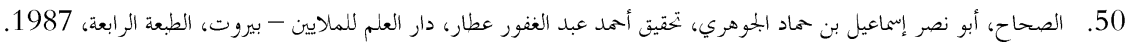

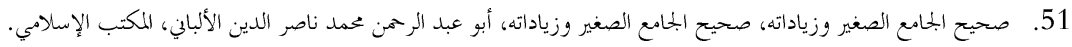

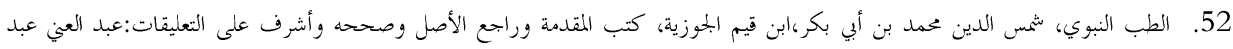

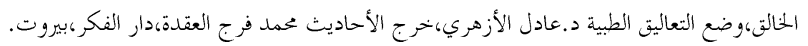

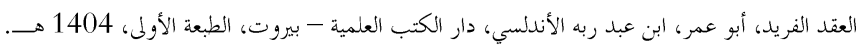

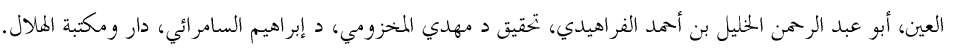

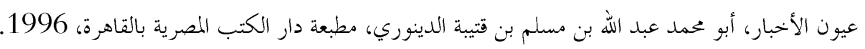

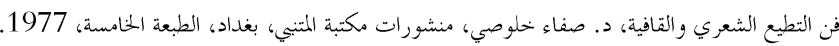

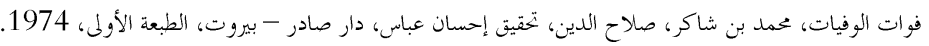

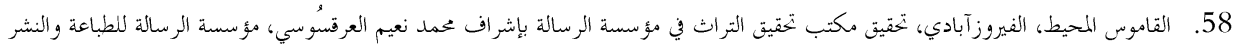

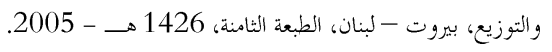

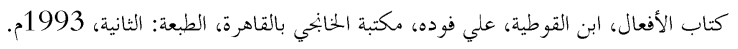

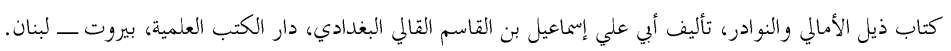

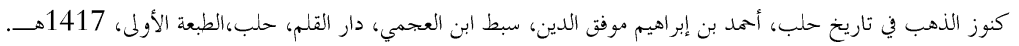

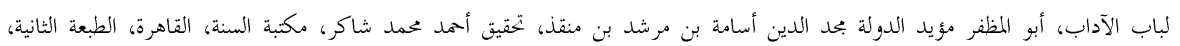

1987م.

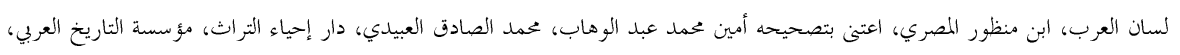

بيروت - لبنان، الطبعة الثالثة، 1997.

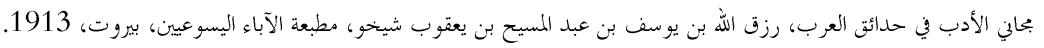

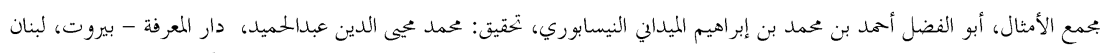

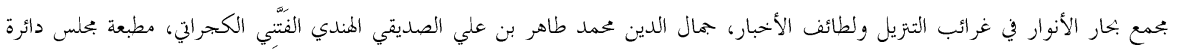

المعارف العثمانية، الطبعة الثالثة، 1967 1967م.

مختارات شعراء العرب لابن الشجري، ضياء الدين أبو السعادات هبة الله ابن الشجري، ضبطها وشرحها محمود حسن زناتي، مطبعة الاعتماد،

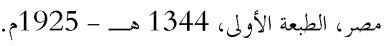

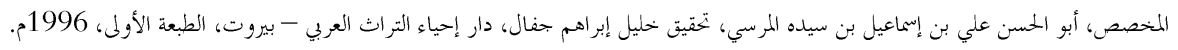

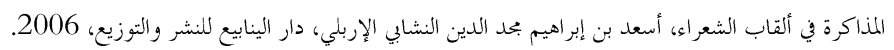
.68

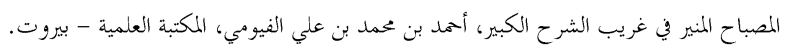

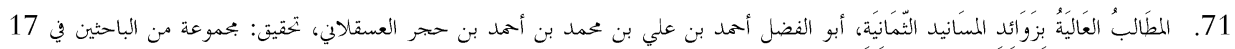

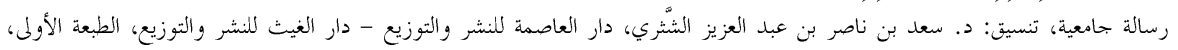

2000

72. المعجم الاشتقاقي المؤصل، د. محمد حسن حسن جبل، مكتبة الآداب - القاهرة، الطبعة الأولى، 2010 مع م.

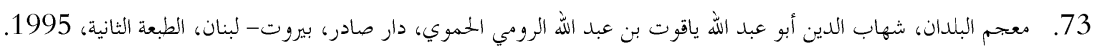

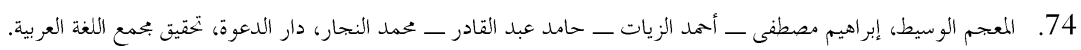

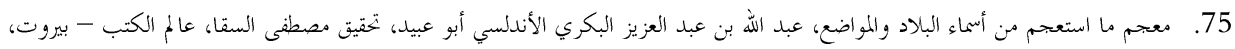

الطبعة الثالثة، 1403.

76. معتم متن اللغة، أحمد رضا، دار مكتبة الحياة - بيروت، 1403.

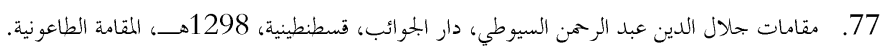

78.

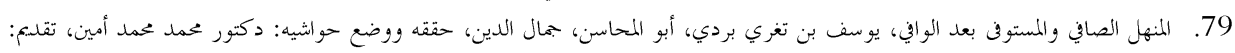
دكتور سعيد عبد الفتاح عاشور، الهيئة المصرية العامة للكتاب.

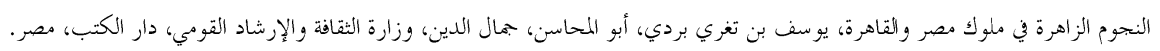


81. الوافي بالوفيات، صلاح الدين خليل بن أيبك الصفدي، تحقيق أهمد الأرناؤوط، وتركي مصطفى، دار إحياء التراث - بيروت، 2000م.

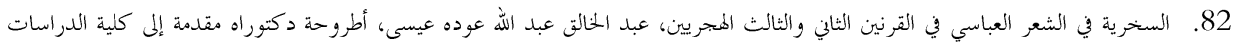

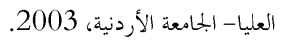

هاء الهجاء الفكاهي في الشعر العباسي بين الضحك والألم، أ.د. ثائر سمير حسن الشمري، بحلة دواة- بحلة فصلية محكمة- المجلد 2، 2016.

(1) (1) تاج العروس، 354/35. (2)

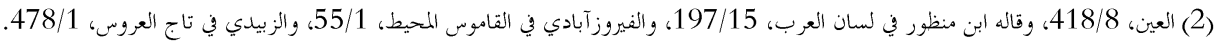

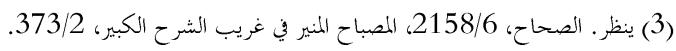

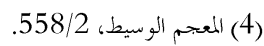

(5) الطب النبوي، 30.

(6) ثمار القلوب في المضاف والمنسوب، 142/1.

(7) من أمراء غسان في أطراف الشام، كانت إقامته بغوطة دمشق. وأدرك الإسلام، ومات على النصرانية. الأعلام، 155/2.

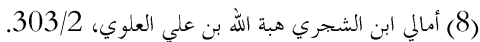

(9) "زيد بن جندب الإيادي الأزرقي: خطيب الأزارقة وأحد شعرائهم. كان ينعت بالمنطيق... كان مختلف الأسنان مشقوق الشفة العليا، ولولا ذلك لكان الكان

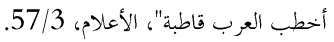

(10) (الحيوان، 6 / 219.

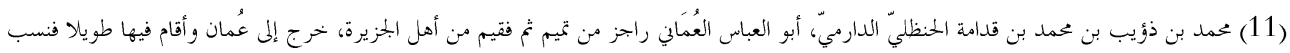

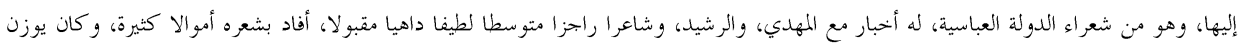

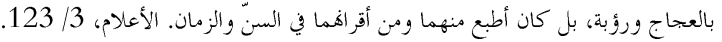

303/2.

(13) المخصص، 54/2.

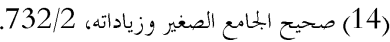

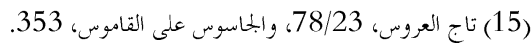

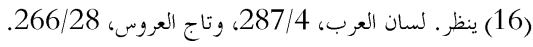

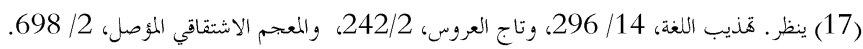

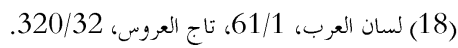

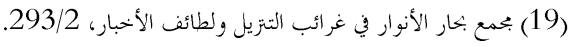

(20) تاج العروس، 170/30.

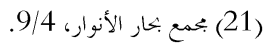

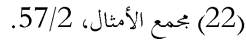

(23) (23) تاج العروم، 100/4)

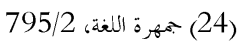

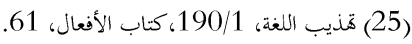

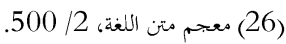

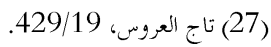

(28) رسائل الجاحظ، 388 الجرس،

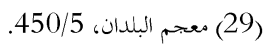

(30) كتاب ذيل الأمالي والنوادر، 82. الموم: أشد الجدري، المهجهج: هجهج بالسبع صاح به ليكف. 


$$
\text { (31) (31) الحيوان، 37 37، كتاب ذيل الأمالي والنوادر، } 847 .
$$

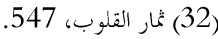

168/2. (33) تاريخ مدينة دمشق، (32)

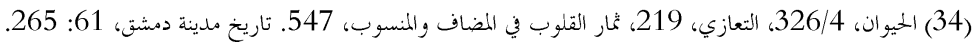
(35) هماسة الظرفاء من أشعار المحدثين والقدماء، 297.

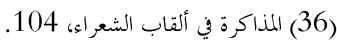

(37) ديوان الأخطل، 19.

70 (38) مقامات جلال الدين عبد الرحمن السيوطي،

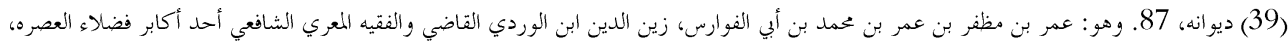

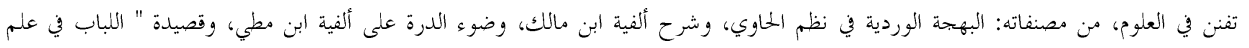

$$
\text { الإعراب، وشر حها، اختصار ملحة الإعراب نظماً، وغيرها. فوات الوفيات، 157/3. }
$$

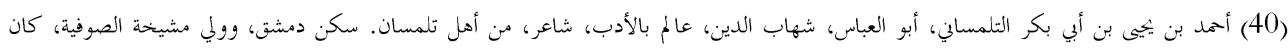

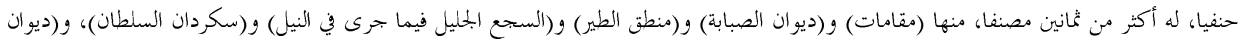

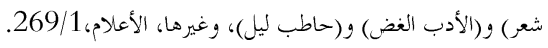

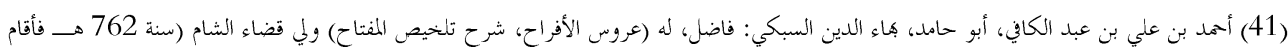

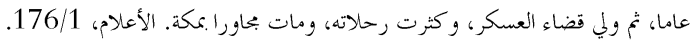

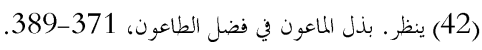

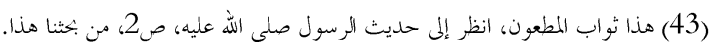

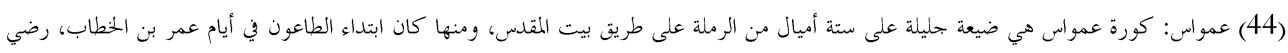

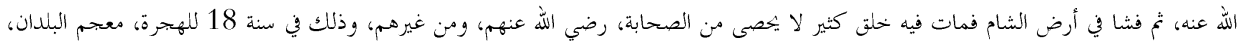

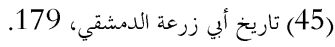

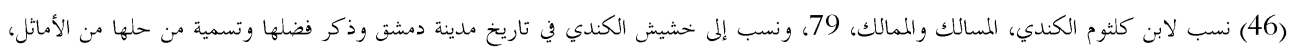

$381 / 16$

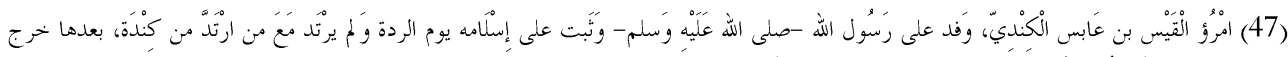

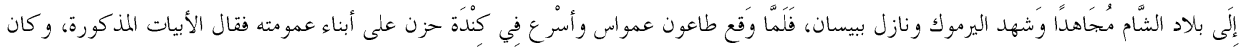

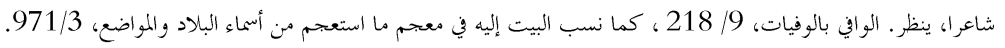

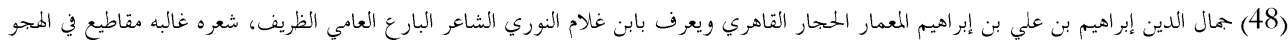

والمجون، تاريخ الإسلام، 14 / 144.

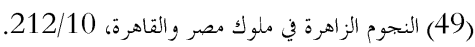

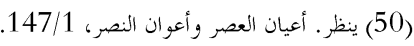

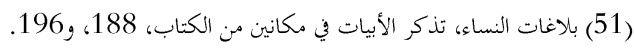

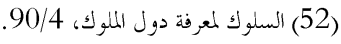

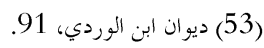

(54) السلوك لمعرفة دول الملوك، 92/4.

(55) المصدر والصفحة نفسها. ولعل كون الطاعون نتيجة أو عقابا على العجب والكبر كانت فكرة شائعة بين الشعراء، فهذا ابن نباتة المصري يكررها،

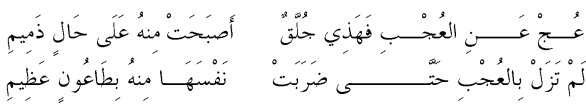

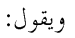




$$
\begin{aligned}
& \text { ديوان ابن نباتة المصري، } 468 . \\
& \text { (56) المصدر والصفحة نفسها. } \\
& \text { (57) فن التطيع الشعري والقافية، } 9 . \\
& \text { (58) المصدر نفسه، } 123 . \\
& \text { (59) السلوك لمعرفة دول الملوك، 123/4. }
\end{aligned}
$$

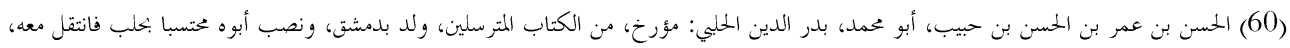

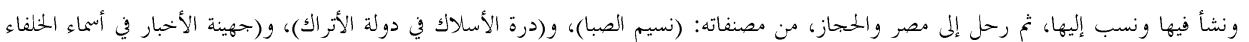

$$
\text { وملوك الأمصار)، وغيرها، الأعلام، 208/2. }
$$

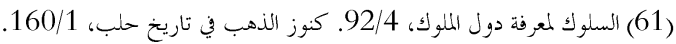

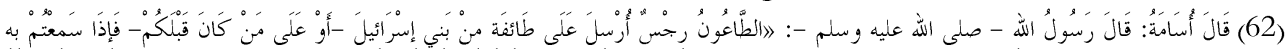

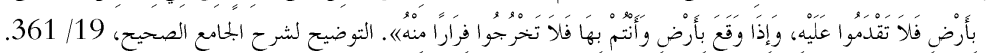

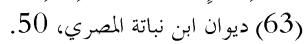

(64) هماسة الخالديين الأشباه والنظائر من أشعار المتقدمين والجاهليين والمخضرمين، 78/1 الماتي،

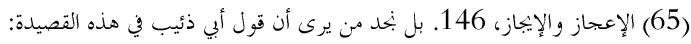

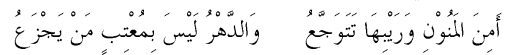

أشعر بيت قالته العرب، ينظر. الدر الفريد وبيت القصيد، 278/1.

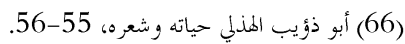
(67) هكذا في العقد الفريد، 230/3، وفي مالكاني الأدب، 216/6، وهو شبل بن معبد بن عبيد بن الحارث بن عمرو بن علي بن بن أسلم بن أحمس البحلي الأمسي عاش في زمن عثمان -رضي الله عنه- و كان له دور كبير في الفتنة وقتها. ينظر الإصابة في تمييز الصحابة، 303/3.

$$
\text { والديار، 327/2 لشبل بن بشر لم أقف على ترجمة له. }
$$

(68) المنازل والديار، 327/2، وبحاني الأدب في حدائق العرب، 6 / 217 ، ، واعتمدنا هذه المجموعة من الكتب في تخريج قصة القصيدة، وأبياها التي

$$
\text { ذكرناها }
$$

(69) قال الأصمعي أهما لعريقة بن ستفع، الأصمعيات، 98، وقيل لكعب بن سعد الغنوي، التذكرة الحمدونية، وقيل أنها لمحمد بن كعب الغنوي، جمهرة

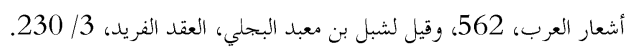

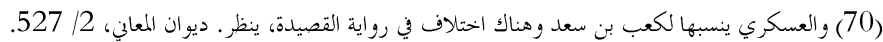

327 / 327 (7) المنازل والدياري

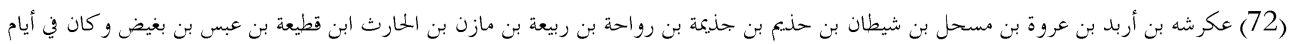

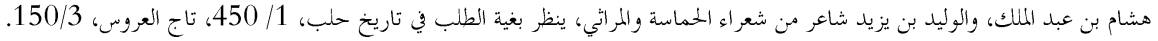

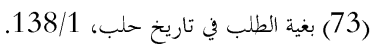

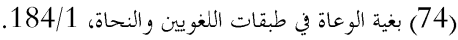

$$
\text { . (75) }
$$

(76) العقد الفريد، 243/3. والأبيات تروى للشُكة أم سليك بن السُكة الصعلوك الجاهلي ترثيه، ينظر. لباب الآداب، 183، وقيل لها أو لأم تأبط شرا،

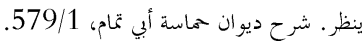

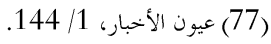
(78) مأم أقف على تعريف بالشاعر.

.

(80) أبو ذؤيب الهذلي حياته وشعره، 64 المعازي

(81) (81) المصدر نفسه.

(82) ديوان الشاب الظريف شمي الدين عحمد بن عفيف الدين التلمساني، 239. 


$$
\text { (83) ديوان ابن عربي الشيخ الأكبر محيي الدين الطائي، } 356 .
$$

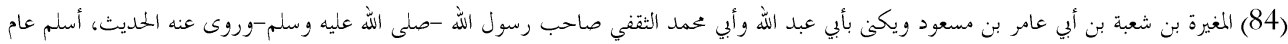

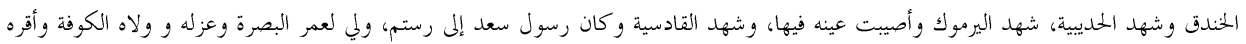

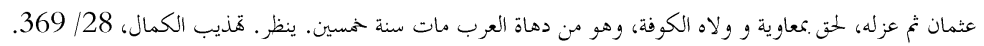

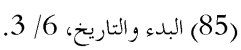

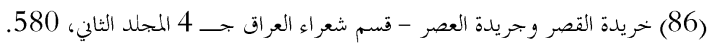

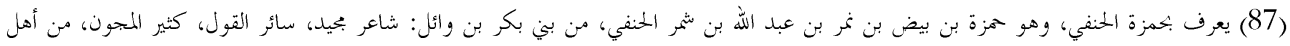

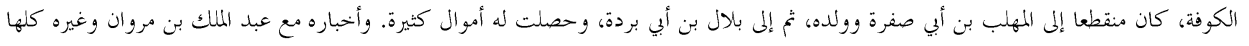

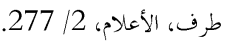

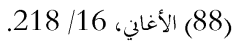

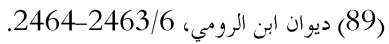

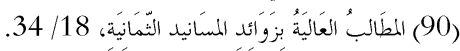
(91) شاعر إسلامي أموي من الشعراء الفرسان له صحبة برسول الله -صلى الله عليه وسلم - وشهد الفتوح في بدء الإسلام، ينظر. الإصابة في تمييز الصحابة، $69 / 5,9 / 5$

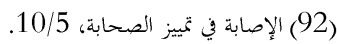

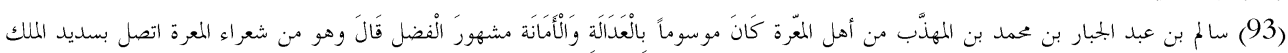

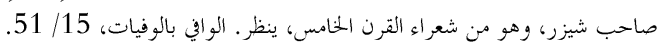

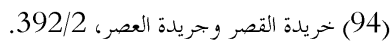
(95) آثار البلاد وأخبار العباد، 206.

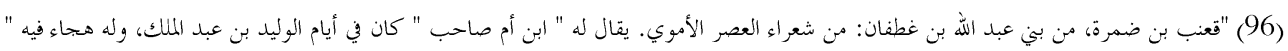
الأعلام، 202/5. (97) ختارات شعراء العرب لابن الشجري، 7/1. كما وصف مدينة شيزر وهي من مدن الشام بكثرة طعنها وطاعوفا لأفا تقع على ثغور الروم وفيها وخمة،

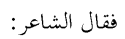

$$
\text { ومخمت وجاورها العدو فأهانها شهاء بين الطعن والطاعونٍ }
$$

بغية الطلب في تاريخ حلب، 146/1.

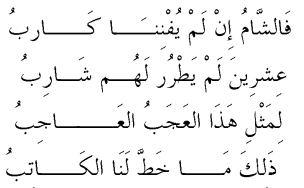

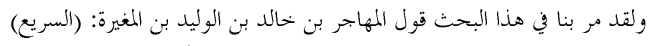

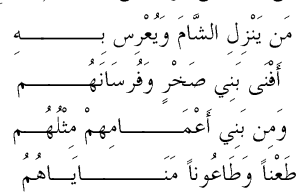

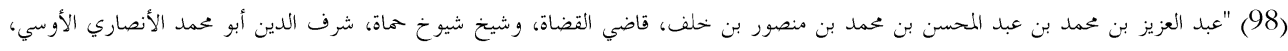

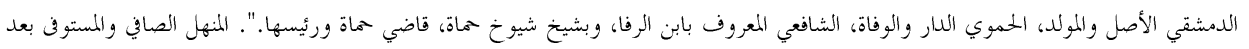




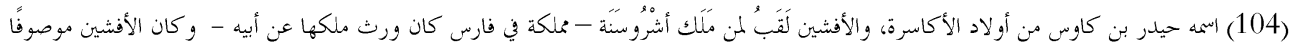

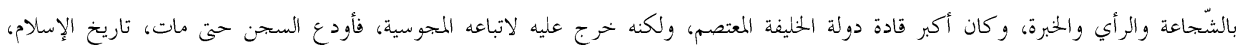

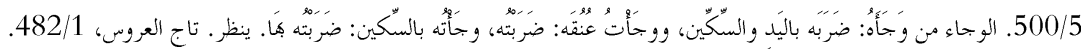

$$
\text { 162/2. 105) شرح ديوان أبي تمام، }
$$

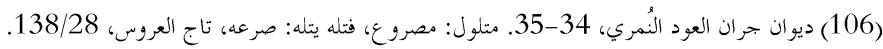

(107)

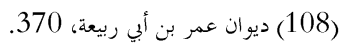

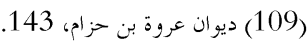

